Economic and epidemic implications of virus containment policies: insights from agent-based simulations

Alessandro Basurto Herbert Dawid Philipp Harting Jasper Hepp Dirk Kohlweyer 


\title{
Economic and epidemic implications of virus containment policies: insights from agent-based simulations*
}

\author{
Alessandro Basurto ${ }^{\dagger} \quad$ Herbert Dawid Philipp Harting $^{\ddagger} \quad$ Jasper Hepp $^{\dagger}$ \\ Dirk Kohlweyer ${ }^{\S}$
}

June 24, 2020

\begin{abstract}
This paper analyzes the implications of different designs of policies, which aim to contain the diffusion of the SARS-CoV-2 virus, with respect to induced economic loss and virus mortality. An agent-based simulation model is implemented and calibrated with German data, which combines the representation of a simple multi-sectoral closed economy with the explicit incorporation of virus transmission channels at the workplace, during shopping activities and other social contacts. It is demonstrated that under a policy resembling German containment measures the model closely reproduces the dynamics of pandemic and economic variables in the aftermath of the COVID-19 outbreak in Germany. Exploring alternative policy designs shows that any efficient policy should impose a low threshold of newly infected for moving from the lock-down to the opening-up stage and in the opening-up stage all restrictions on economic activity should be lifted. With respect to the reduction of consumption activities during the lock-down a trade-off between the induced GDP loss and the resulting mortality emerges. Regardless of the chosen design of the containment measures, the introduction of complementary economic support measures substantially reduces the induced GDP loss and leads to a reduction of the public debt accumulated during the considered time interval. The efficient design of containment policies changes substantially if lifting economic restrictions during the opening-up stage also results in reduced effectiveness of the individual prevention measures by agents.
\end{abstract}

Key Words: COVID-19, economic loss, containment policy, exit strategy, agent-based modeling

\section{Introduction}

The outbreak of the COVID-19 pandemic in a large number of countries all over the globe after November 2019 has lead to the introduction of partly severe containment measures

\footnotetext{
*This research has been supported by the European Unions Horizon 2020 grant No. 822781 - Project GROWINPRO. (0) 2019. This manuscript version is made available under the CC-BY-NC-ND 4.0 license. The authors gratefully acknowledge the Center for Parallel Computing at the University of Paderborn for providing computational resources on the OCULUS high-performance computing cluster and are grateful to Michael Neugart for helpful comments and to Adrian Philipp Dawid for support in implementing the model.

${ }^{\dagger}$ Bielefeld Graduate School of Economics and Management (BiGSEM), Bielefeld University

${ }^{\ddagger}$ ETACE and Center for Mathematical Economics, Bielefeld University, hdawid@uni-bielefeld.de

${ }^{\S}$ ETACE, Bielefeld University
} 
in most of the affected regions. Many of these measures have substantial implications for economic activity. Examples in this respect are the closure of stores, restaurants and other business outlets, the increased use of home-office, travel-bans or complete lock-downs preventing potential customers or service providers to interact. There is a substantial heterogeneity in the measures implemented by different policy makers ${ }^{1}$ and in light of the severe economic downturn resulting from the COVID-19 pandemic and its containment it is crucial to develop a thorough understanding of the joint dynamic epidemiological (number of infected, mortality) and economic (GDP loss, sectoral unemployment) effects of the different measures. Whereas well-established epidemiological models (see Kissler et al. (2020)) can be employed to address the first of these issues, rigorous approaches for studying simultaneously the dynamics of the transmission of the virus and of economic activity are still sparse. Considering these two aspects in an integrated framework is important not only because many containment measures have direct economic effects, but also because several main infection channels are directly related to economic activity. In particular, this applies to the potential transmission of the virus at the work-place, at stores and during the consumption of services.

In this paper we analyze epidemic and economic implications of different policies based on a unified dynamic agent-based simulation model populated by age-structured households (young/old) and heterogeneous firms, which incorporates both the spreading of an infectious and potentially mortal virus in the population and a simple multi-sectoral macroeconomic structure. The dynamics of the transmission of the virus between individuals is based on a standard SIRD model with three channels for contacts between agents: i) meetings at the workplace, ii) contacts while purchasing consumption goods and consuming services and iii) private meetings. From an economic perspective we depict a simple production economy with one public and three private sectors (manufacturing, service, food) populated by heterogeneous firms. Sectors differ with respect to the firms' average labor productivity and the average number of contacts between agents when purchasing and consuming the good. Relying on an agent-based approach, we explicitly model the evolution of the workforce of each employer as well as the exact interactions between consumers and producers, which allows us to keep track of the number and structure of contacts associated with the different economic activities. This detailed representation of the economic interaction structure allows us to represent a wide range of specific measures associated with virus containment policies in our modeling framework. That includes temporary (partial) closures of stores in different sectors, (sector-specific) changes in the frequency of home-office, changes in the (age-specific) shopping and private meeting patterns and also economic support policies like firm bailouts and public support for workers whose job is jeopardized due to the economic effects of the pandemic. This richness in structure distinguishes our approach from existing unified theoretical studies of economic and epidemiological dynamics (see e.g. Eichenbaum et al. (2020); Krueger et al. (2020); Acemoglu et al. (2020)), which rely on substantially more abstract models and do not allow to distinguish between different types of policy measures in a detailed way comparable to our setting.

The design of the economic part of the model, in particular with respect to the structure of the individual decision rules as well as the market interaction protocols, builds strongly on a well established agent-based macroeconomic framework, namely the Eurace@Unibi model, which has been already used for the analysis of a wide range of economic policy

\footnotetext{
${ }^{1}$ See http://covid19-interventions.com/ and https://www.imf.org/en/Topics/imf-and-covid19/ Policy-Responses-to-COVID-19 for an international comparison of policy responses to the COVID-19 threat.
} 
issues (e.g. Dawid et al. (2014, 2018, 2019)). Nevertheless, the model employed here is not an extension of the Eurace@Unibi model, but a separate agent-based model designed for the analysis of the interplay of economic activities and virus transmission, which has also been implemented independently from the Eurace@Unibi model. ${ }^{2}$ For the parametrization of the model, on the one hand we rely on established empirically founded parameter values from the Eurace@Unibi model, and, on the other hand, we employ a large range of empirical sources. Apart from epidemiological data we use studies about the structure of contacts emerging from work, consumption activities and private meetings, about the sector specific maximal fraction of workers who can move to home office as well as about the fraction of actually infected individuals who are also reported to be infected. The number of intensive care units in the model and age dependent individual case fatality (depending on the utilization of the intensive care units) are taken from German data as well as the values for sector-specific average labor productivity and the demographic structure of the household population. The probability that a susceptible individual gets infected at a single contact to an infectious individual is calibrated such that the model generates an initial reproduction factor of $R_{0}$ around 2.7 in the absence of containment measures, which lies within the interval of $[2.5,3]$, which has been empirically estimated for this factor (see e.g. Read et al. (2020)). We establish empirical credibility for our framework by showing that the calibrated model does not only generate (stationary) unemployment and GDP dynamics closely resembling German data, but is also able to reproduce the actual dynamic evolution of the reported number of infected and the reproduction factor $R_{0}$ for the time window between the early occurrence of the virus in Germany (March 9, 2020) and a point in time after relaxation of the most stringent containment measures (May 9, 2020) ${ }^{3}$.

Our policy analysis then proceeds in three steps. First we compare the effect of different designs of the containment policy on the dynamics of infected households and mortality of the virus as well as on key economic indicators, in particular GDP loss relative to the status-quo before the outbreak of the virus. ${ }^{4}$ We assume that all policy responses induce individual prevention measures by all agents, thereby reducing the infection probability at each contact between an infectious and a susceptible agent. Also, we assume that as long as no vaccine is available, a fraction of workers is in home office. Additionally, the policy might foresee constraints with respect to private contacts and a restriction of the possibilities for consumption of manufacturing and service goods. All containment policies have two stages, a 'lock-down stage' and an 'opening-up stage', and each policy is characterized by three key parameters: i) the amount of restrictions in the lock-down stage; ii) the amount of restrictions in the opening-up stage; iii) the timing of the transition from lock-down to opening-up (and potentially vice-versa) expressed as a threshold for reported newly infected per week below (above) which the lock-down stage is ended (activated). In addition to exploring how the choice of these three parameters influences the effectiveness of the policy, we also study the costs, both in terms of casualties and GDP loss, that is associated with delaying the initial introduction of the policy. The second step of our analysis studies how the economic costs associated with containment policies can be alleviated by complementary public transfer schemes preventing bankruptcies of firms and unemployment of workers. Whereas these first two steps provide general insights about

\footnotetext{
${ }^{2}$ The model has been implemented in Julia, the code is open source and can be obtained from https: //github.com/ETACE/ace_covid19.

${ }^{3}$ Since the timing and details of the containment measures in Germany differed between states, we implement a slightly simplified representation of the actual policy response in our model.

${ }^{4}$ Our analysis focuses entirely on economic costs of virus containment measures. Obviously there are other important social costs associated with several of the considered measures, which, however, are hard to quantify. In this paper we do not explicitly consider such effects.
} 
the design of effective policies and the trade-off between the overall number of infected and the economic costs, the third step of the analysis returns to the German scenario and explores the effect of different opening-up strategies conditional on the fact that a relatively long lock-down stage has already been implemented.

Our main findings can be summarized as follows. Under the assumption that the effectiveness of individual prevention measures remains unchanged during the lock-down and the opening-up stages, any efficient policy should impose a low threshold of approximately 5 reported weekly newly infected per 100.000 people. In the opening-up stage all restrictions on economic activity should be lifted. With respect to the reduction of consumption activities during the lock-down, no optimal value can be identified, but there emerges a trade-off between the induced GDP loss and the resulting mortality. Although weaker restrictions during the lock-down stage imply a longer duration of the lock-down, they result in lower economic costs, but also in higher mortality. The efficient policy design changes if the effectiveness of the individual prevention measures decreases during the opening-up stage. In such a scenario policies with strong lock-down measures should be followed by only a weak relaxation of the restrictions during the opening-up phase. Regardless of the chosen design of the containment measures, the introduction of complementary economic support measures substantially reduces the induced GDP loss and thereby also leads to a reduction of the public debt accumulated during the considered time interval of 18 months. In case the lock-down period, like in many countries, has already been extended to several weeks a second wave of infections is unlikely, if the effectiveness of individual prevention measures remains unaltered. If the individual infection probability is, however, increasing, the optimal policy is to set a very low threshold in order to immediately react to and avoid an upcoming second wave.

The quickly growing economic literature investigating the COVID-19 pandemic on a theoretical level mainly builds upon the standard SIR model and introduces a link to economic activity. Measures taken to contain the pandemic thereby typically reduce production potential or consumption and hence induce an economic shock. The interplay between containment measures and economic costs is then studied as a pure optimization problem from a social planners point of view (Alvarez et al., 2020; Miclo et al., 2020), or embedded in a simple macroeconomic framework, where agents individually optimize their decisions (Acemoglu et al., 2020; Eichenbaum et al., 2020; Krueger et al., 2020; Jones et al., 2020). The empirical economic literature attempts to estimate the impact of COVID-19 based on surveys (Coibion et al., 2020), analysing input-output-tables (Fadinger and Schymik, 2020; Pichler et al., 2020) or using detailed output data on a sectoral level (Dorn et al., 2020).

Agent-based simulation models have been used to asses the effectiveness of containment policies in purely epidemiological studies (Adam, 2020), for example for US and UK (Ferguson et al., 2020), for Finland (Tuomisto et al., 2020) or for Australia (Chang et al., 2020). Even though the potential of agent-based models has been emphasized in epidemiology after the outbreak of the swine flu pandemic in 2009 (Epstein, 2009) as well as in economics after the financial crisis in 2008 (Foley and Farmer, 2009), to the best of our knowledge we are the first to combine a macroeconomic framework with an epidemiological structure in an agent-based model. ${ }^{5}$

The paper is organized as follows. In Section 2 we give a brief description of the structure of the model focusing on the economic and pandemic frameworks and on their calibration.

\footnotetext{
${ }^{5}$ Additionally, online laboratories like TRACE (Hammond et al., 2020) or ASSOCC (Ghorbani et al., 2020) aim to provide policy makers with tools to investigate containment measures in a fast and easy manner.
} 
In Section 3 we provide the reproduction of German data with respect to key economic and pandemic variables. General results of our analysis are discussed in Section 4, while Section 5 analyzes different exit scenarios. We conclude in Section 6. In the Appendix we provide a detailed model description and the parameter setting as well as statistical tests underlying our analysis.

\section{The Model}

In this section we provide a short description of our model, which highlights the overall structure of the economy as well as the crucial assumptions and mechanisms driving the economic and pandemic dyanmics. A more detailed and technical presentation of the model is given in Appendix A.

\subsection{The Economy}

The economy is populated by $m_{t}$ households and $n_{t}$ firms. The population of households is divided in a fraction $a_{t}^{Y}$ of young households and a fraction $1-a_{t}^{Y}$ of old individuals. Young households constitute the labor supply of the economy, whereas old households live on a pension that is paid through a pay-as-you-go system.

Firms Firms are distributed across three private sectors representing a manufacturing $(\mathrm{M})$, service $(\mathrm{S})$ and a food $(\mathrm{F})$ sector, where in the food sector we subsume all essential products for daily life. For each sector there is a mall representing the physical locus of commercial transactions in that sector. In the mall, the $n_{k, t}$ firms active in sector $k \in$ $\{M, S, F\}$ keep an inventory that is replenished once per week and from which products are sold to households on a daily basis. A firm $i$ is characterized by a firm-specific productivity level $A_{i}$ and employs $L_{i, t}$ workers in period $t$ to produce a weekly output $Q_{i, t}$ according to the production function $Q_{i, t}=A_{i} L_{i, t}$. The production and input planning of the firm is based on adaptive demand expectations and the managing of the inventory stock kept in the mall to satisfy the volatile demand of households. The adjustment of the workforce, in case of an output reduction, is fully flexible, whereas it is subject to matching frictions on the labor market in case of an output expansion. The wage $w_{i}$ paid to workers is identical for all firms active in the same sector and is proportional to the average productivity in the sector.

Firms apply mark-up pricing with an endogenous mark-up $\mu_{i, t}>0$ on unit costs to determine the price $P_{i, t}$ of their products. Unit costs consists of the variable labor costs and fixed $\operatorname{costs} c_{i}^{F}$. The mark-up evolves adaptively over time within an interval $[\mu, \bar{\mu}]$ and positively depend on the firm's market share. Depending on its liquidity level, the firm pays out either a fraction $\zeta$ or, if the liquidity exceeds a threshold, the full amount of (positive) net profits as dividends. Dividends and the fixed costs paid by the firms are equally distributed to households. ${ }^{6}$ A firm with negative liquidity has to declare bankruptcy and exits the market. Since our analysis focuses on a short time period (18 months) characterized by economic crises, we abstain from incorporating a market entry mechanism into our model.

\footnotetext{
${ }^{6}$ Since our model does neither have a financial market, where households could buy shares of the firms, and also does not have an explicit capital goods sector through which firms' expenditures for fixed costs (e.g. capital costs) are channelled back to households, we ensure that the monetary flow in the model is closed in this simplified way.
} 
Households While old households are retired, young households are active on the labor market. Each household has appropriate skills to work in one of the sectors of the economy. The proportion of the labor force with skills for sector $k$ is denoted by $e_{k}$. Depending on their age and employment status, households have different income sources. Employed households earn a weekly labor income. Unemployed households, instead, receive unemployment benefits that correspond to a fraction of the last labor income. Old households live on a pension that is uniform for all retirees in the economy. Additionally, all households receive a capital income that corresponds to a proportional share of firms' fixed costs and dividends distributed by the firms.

The decision of a household $h$ on how much to spend for consumption is based on a buffer-stock saving heuristic well established in the literature (see Deaton (1991)). This rule prescribes to spend the average net income $\bar{I}_{h, t}^{N}$ as long as household's current wealth corresponds to a desired wealth-to-income ratio $\Phi$. Otherwise the spending has to be adjusted accordingly to let the current wealth level converge towards the desired one. The consumption budget is allocated across the three sectors according to fixed consumption quotas $c_{k}$. However, since the food sector produces essential goods, households try to avoid large spending cuts for food in case of income drops. In this situation, households reduce the expenditures for food only by a small fraction $\phi$ per period, and allocate the remaining budget proportionally among the non-essential sectors.

Labor Market Interactions The labor market of the economy is a decentralized market in which, at the beginning of every week for each sector separately, firms open vacancies in a random sequence and unemployed job seekers with appropriate skills apply. The firm then hires on a first-come-first-serve basis. If at the time of the announcement of the job opening there are no unemployed job seekers with appropriate skills, the firm is rationed and can only hire again in the following week. If firms decide to reduce their labor force, they randomly pick the workers to be laid off.

Goods Market Interactions On randomly picked different days of the week, a household visits one of the sector-specific malls for shopping. When visiting a mall, the household chooses the firm to buy from by collecting price information from a set of $\eta$ randomly selected active suppliers at the mall. The decision which of these $\eta$ products to purchase is based on a standard logit choice model that takes product prices $P_{i, t}$ of the different suppliers weighted with a sensitivity of choice parameter $\gamma^{C}$ into account.

All households with the same shopping day and the same product choice queue in random order for purchasing the selected good. If the available mall inventories of the firms selected by the consumers are sufficient to serve all demand on that day, then all households are fully served. If the stock of a firm at the mall becomes empty, then the firm is an inactive supplier until the next production day. If all suppliers at a mall are inactive, then consumers attending the mall are rationed.

Public Sector Besides the three private sectors, there is also a public sector operated by the government. The public sector provides administrative services that are not sold on the product market. The government employs a fraction $e_{P}$ of the labor force as civil servants. Civil servants have a secure job and work in one of $n_{P}$ offices.

The government collects income and profit taxes to fund its civil servants, and to pay unemployment benefits to young households without a job and pensions to old households. Additionally, the government can pay subsidies or other financial support to households 
and firms as part of supplementary policies. The government adjusts the tax rate $\tau_{t}$ over time in order to keep a target level of the public account.

\subsection{Social Interactions}

Social interactions between households take place at three different occasions. The first one describes work-related contacts capturing that employed households meet workers employed at the same firm. The maximum number of potential contacts $n_{k}^{w}$ that a worker can have every workday is sector specific. The second occasion are social contacts that occur during shopping, which is supposed to capture that households meet other shoppers visiting the same mall at the same day. For the service sector this also includes contacts during the consumption of a service, e.g. at a restaurant, a fitness studio or similar. The total number of shopping contacts $n_{k}^{c}$ of a households per day is sector-specific and the actual number of contacts is between 0 and $n_{k}^{c}$. Finally, there are other social contacts that happen in other contexts than working and shopping. A distinction is thereby made in the frequency of social interaction between age groups. There is an upper bound for the number of intra-generational meetings between a young individual and other young households and an old individual with old households $\left(n_{y, y}^{p}\right.$ and $\left.n_{o, o}^{p}\right)$, and for inter-generational contacts between a young individual and old households and vice versa $\left(n_{y, o}^{p}\right.$ and $\left.n_{o, y}^{p}\right)$. For each of the channels the actual number of meetings of an agent during a day is chosen from a uniform distribution between 0 and the corresponding upper bound.

\subsection{Pandemic Dynamics}

The modeling of the pandemic dynamic follows a standard SIRD approach. In the presence of a pandemic, households can be in one of four states with respect to their health status. Households can be susceptible, i.e. they have not been exposed to the virus and are therefore still not immune. Households can be infected, where one can distinguish three different phases of the infection that is a latency, an infectious and a post-infectious period. And finally households can either be recovered, which means they have been infected and survived, or deceased meaning they have died from the infection. We assume a fixed recovery time $\bar{t}_{r e c}$ as well as a fixed latency period $t_{l n t}$ and infectious period $t_{\text {inf }}$.

Contagion and therefore the transmission of the virus takes place when susceptible households have contacts with infectious individuals during work, shopping and in other social occasions. The contagion of a susceptible household through an infectious individual is subject to uncertainty, which is captured by an infection probability $p_{\text {inf }}$. The infection probability is the same regardless of the type of social interaction.

An infected household recovers after $\bar{t}_{r e c}$ days and is then immune against a second infection. However, there is a certain probability that an infected individual passes away in the course of the infection. The individual fatality rate for an infected agent depends on the age, but also on the capacity utilization of intensive care units of the health system. The economy has a capacity $n^{i c u}$ for patients who can be treated in intensive care units and it is assumed that a fraction $u^{i c u}$ of infected agents needs intensive care. In case the intensive care units are underutilized, then the fatality rate $q_{t}^{a}$ of an agent with age $a \in\{y, o\}$ equals $\bar{q}_{l}^{a}$. If, however, the required number of intensive care beds exceeds the available ones, then the fatality rates increase in the size of the shortfall such that the actual fatality rate is a weighted average of $\bar{q}_{l}^{a}$ and $\bar{q}_{h}^{a}$, where $\bar{q}_{h}^{a}$ is the mortality rate if no intensive care can be provided. Moreover, old individuals have generally a higher fatality from the infection than young ones implying that $\bar{q}_{l}^{y}<\bar{q}_{l}^{o}$ and $\bar{q}_{h}^{y}<\bar{q}_{h}^{o}$. 
Before the outbreak of the pandemic, all households are susceptible and the number of susceptible individuals corresponds to the number of households $m_{0}$. At a specific point in time $t_{0}$, a small number of randomly selected households gets infected. These first patients pass the virus to other individuals through their social interactions at work, during shopping or at other occasions thereby starting the infection dynamics. It is assumed that after $t_{v a c}$ days from the beginning of the pandemic, a vaccine is available on the market and then, all susceptible households are assumed to receive immediate vaccination. Thus, the probability of infection $p_{\text {inf }}$ becomes zero and the pandemic washes out as soon as infected households recover or die.

\subsection{Calibration and Initialization}

Economic Calibration We initialize the model with $m_{0}=100.000$ households and $n_{0}=3780$ firms (private and public). The number of households is chosen to balance the trade-off between having a sufficiently large population size and technical limitations. The total number of firms, instead, has been chosen to match the relation between the size of the working population and the number of private firms in the German economy. ${ }^{7}$

Following German demographic data we set the fraction of young households $a_{0}^{Y}=75 \%$ capturing that the number of individuals belonging to the age group between 18 and 65 years in the German population is about three times that of individuals with an age above 65 years. $^{8}$

The productivity level of a firm $i$ in sector $k$ is a random variable following a uniform distribution from an interval around a sector-specific average productivity $\bar{A}_{k}$ taken from Statistisches Bundesamt (2020). Sectoral wages are proportional to the average productivity in the sector and their level is chosen such that the average price, taking into account (average) firm mark-ups and fixed costs in each sector (given the firm's markup) is equal to one. Productivity and wages are measured in units of $1.000 / 52 €$, such that a weakly output of 1 unit corresponds to an annual GDP of $1.000 €$. The parameters determining the allocation of households consumption expenditures across the three private sectors, $c_{M}=21 \% c_{S}=50 \% c_{F}=29 \%$, are based on German data and so is the employment share of the public sector $e_{P}=12 \%$. The labor supply in the three private sectors manufacturing, service and food, i.e. the fraction of the labor force with the corresponding skills, is given by the estimated employment shares $e_{M}=11.70 \%, e_{S}=43.62 \%$ and $e_{F}=32.68 \%$. These shares are calculated based on the allocation of consumption expenditures across the three sectors and the average labor productivities . The initial number of workers in sector $k$ is $m_{0} \cdot e_{k}$ and the initial number of firms or, respectively, offices equals $n_{k}=e_{k} n_{0}$. The properties of the sectoral structure are summarized in Table $1 .{ }^{9}$

The economic parameters and the initial values of specific agent variables are calibrated to generate a stationary GDP per capita and unemployment rate that reasonably match the German economy before the pandemic. In particular, the model generates on average across 20 batch runs an annual GDP per capita of $43.013 €$ and an unemployment rate of $3.98 \%$ (compared to an annual GDP per capita of $41.350 €$ and an average unemployment

\footnotetext{
${ }^{7}$ The initial population state we use for all our simulations has been generated by running our model for a burn-in phase of 2300 periods. Without the appearance of the virus and any change in the policy parameters the model exhibits stationary dynamics of the economic key variables like GDP and unemployment starting from this initial state.

${ }^{8}$ The German demographic data we obtain from here and firm data from here.

${ }^{9}$ Private sector employment shares for Germany are from here and the employment share of German public sector from here. The data taken for sector-specific productivity is taken from the Volkswirtschaftliche Gesamtrechnungen for Germany (Statistisches Bundesamt, 2020) and can be found here.
} 
Table 1: Sectoral distribution.

\begin{tabular}{lcccc}
\hline & Manufacturing & Service & Food & Public \\
\hline Employment share & $11.70 \%$ & $43.62 \%$ & $32.68 \%$ & $12.00 \%$ \\
Av. productivity & 97 & 62 & 48 & 62 \\
Productivity range & $87.3-106.7$ & $58.9-65.1$ & $43.2-52.8$ & 62 \\
Av. wage & 76.5 & 50.1 & 38.8 & 59.2 \\
Consumption shares & $21 \%$ & $50 \%$ & $29 \%$ & - \\
\hline
\end{tabular}

Table 2: Upper bound of social interactions: work and consumption.

\begin{tabular}{lcc}
\hline Sector & Work & Shop \\
\hline Manufacturing & 8 & 10 \\
Service & 8 & 28 \\
Food & 8 & 10 \\
Public & 8 & - \\
\hline
\end{tabular}

Table 3: Upper bound of social interactions: social activity.

\begin{tabular}{lcc}
\hline & Young & Old \\
\hline Young meets & 5 & 2 \\
Old meets & 4 & 2 \\
\hline
\end{tabular}

rate of $3.2 \%$ in 2019 , see here).

Social Interaction Calibration The total number of social interactions is the sum of all social contacts at different occasions. We model three different contexts for social interactions and use data reported in Mossong et al. (2008) to calibrate the average number of private contacts for an agent each day as well as the contacts when she is going to work or shopping in a certain sector. First, we assume that an employee meets on average 4 coworkers during one working day (given a distribution with upper bound $n_{k}^{w}=8$ ). Second, a household interacts with other households that go shopping in the same mall at the same day. Taking into account that a household in each sector shops only once a week, we use $n_{M}^{c}=10, n_{S}^{c}=28$, and $n_{F}^{c}=10$ where, in line with Mossong et al. (2008), the number of potential meetings during consumption of services is considerably higher compared to the other types of goods. And finally, the average number of social interactions per day during leisure time across different age groups is again derived from the data reported in Mossong et al. (2008). This gives the parameters $n_{y y}^{p}=5, n_{o o}^{p}=2, n_{y o}^{p}=2$, and $n_{o y}^{p}=4 .{ }^{10}$ The calibrated data on social interactions is summarized in Table 2 and 3.

Pandemic Calibration Our model is calibrated to replicate the current pandemic of the SARS-CoV-2 virus in Germany. Since the pandemic is still ongoing, there is a considerable uncertainty around key parameters of the virus. Our choice of parameters is consistent with the current data on COVID-19. The initial fraction of population infected is based on reported number of infected in Germany on the 9th of March 2020. Since not all patients infected with SARS-CoV-2 show symptoms, the estimated number of infected individuals differs substantially from the detected number of cases. Bommer and Vollmer (2020) use the infection and fatality rate from Verity et al. (2020) to estimate a detection rate in Germany. We use their result that $15 \%$ of infected are reported to link the number of infected in our model to data giving the reported number of infections. Taking this into account and scaling the number of reported infected in Germany on March 9, 2020 to our population size of 100.000 households yield an initial number of 8 young and 3 old infected

\footnotetext{
${ }^{10}$ Our parameter value $n_{y o}^{p}=2$ is higher than the value directly derived from the numbers given in Mossong et al. (2008). This adjustment has been made in the process of calibrating our model dynamics to the German data.
} 
Table 4: Data on COVID-19.

\begin{tabular}{lc}
\hline Name & Value \\
\hline Recovery period & 21 days \\
Infectious period & 5 days \\
Latency period & 5 days \\
Detection rate & 0.15 \\
Reported infections in need of intensive care & $8.5 \%$ \\
Intensive care units (ICU) & 30 per 100.000 \\
& \\
Infection probability when & $7.25 \%$ \\
susceptible meets infectious & \\
\hline
\end{tabular}

Table 5: Fatality rates

\begin{tabular}{lc}
\hline Name & Value \\
\hline Below ICU capacity & \\
Young & $0.099 \%$ \\
Old & $2.4 \%$ \\
Without ICU treatment & \\
Young & $0.27 \%$ \\
Old & $7.5 \%$ \\
\hline
\end{tabular}

households in our model.

The actual value of $p_{\text {inf }}$, the probability to be infected when meeting a contagious individual, is unknown in the literature. Instead, this value is calibrated such that in a scenario without any virus containment measures the average reproduction number in initial periods before herd immunity starts to play a role matches the value of $R_{0} \approx 2.7$ and hence lies well within the standard range of values reported for this number (see e.g. Read et al. (2020)). Upon infection, households, after a latency period of five days $\left(t_{l n t}=5\right)$, are infectious for five days $\left(t_{i n f}=5\right)$ (World Health Organisation, 2020).

In case a household gets infected, it takes $\bar{t}_{r e c}=21$ days to recover. During this time, the household might pass away. The calibration of the individual case fatality rate for the case of not fully utilized intensive care capacities relies on age-structured German data of casualties and reported infected as of the beginning of June 2020, where the total number of reported infected has been allocated to different age groups following Robert Koch Institut (2020). In that case, the fatality rate for individuals below 65 years is $0.66 \%$ of reported infected. For individuals older than 65 years this rate is $16 \%$. Taking into account that only 15 percent of infected are reported, we obtain $q_{l}^{y}=0.099 \%$ and $q_{l}^{o}=2.4 \%$. In case of a congestion of intensive care capacities, we use $q_{h}^{y}=0.27 \%$ for young and $q_{h}^{o}=7.5 \%$ for old patients. To capture the effect of a collapsing health system, we extrapolate Italian data collected during periods of over-utilization of local intensive care capacities, see here).

Following Anesi (2020), an infected household needs intensive care in $8.5 \%$ of the reported cases. The assumed number of intensive care beds is 30 per 100.000 households, which is based on German data (Rhodes et al., 2012). Finally, we assume that a vaccine will be available one year after the initial spread of the virus. The pandemic related data for our calibration is summarized in Tables 4 and 5 .

\subsection{Containment Measures and Economic Policy Instruments}

In our policy experiments we analyze the pandemic and economic implications of different policy measures aimed at containing the outbreak of the COVID-19 pandemic. We thereby explicitly distinguish between four sets of measures as part of a containment strategy implemented to control the pandemic spread of the infection, and economic policy instruments to mitigate the severe economic consequences of the pandemic and of some of the implemented countermeasures.

Containment Measures The first set of measures targets the individual behavior of households, aiming at a direct reduction of the infection probability $p_{\text {inf }}$ during face-toface contacts of individuals. These measures include keeping a minimum physical distance, 
improved measures of sanitation, and wearing masks or other facial coverings. We refer to these measures as individual prevention measures and assume that they reduce the infection probability to $(1-\xi) p_{\text {inf }}$ with $\xi \in(0,1)$.

The second bundle of measures aims at a reduction of social interactions in the private context. This social distancing can either be achieved through contact restrictions imposed by the government or through a consensual change in the behavior of households. Studies show that there has been a substantial reduction in the number of social contacts in Germany after the outbreak of COVID-19 (see Lehrer et al., 2020). In our model, social distancing is captured by a reduction of the average number of daily intra- and intergenerational social contacts, which can be achieved by reducing the upper bounds $n_{y y}^{p}$, $n_{o o}^{p}, n_{y o}^{p}$ and $n_{o y}^{p}$ of the stochastically determined number of contacts.

The third component of the containment strategy prescribes social distancing also in the professional context. This includes the reduction of direct contacts between workers at the workplace, for example, by changing work flows, processes, and by conducting meetings online. The main instrument in this respect is the introduction, respectively extension, of home-office. ${ }^{11}$ To account for sectoral differences, we assume that in each sector only a certain proportion of workers $h_{k}^{h o}$ works from home during the pandemic. We use fractions of (potential) jobs, suited for working from home, in different sectors reported by Fadinger and Schymik (2020). In particular, we use $h_{M}^{h o}=45 \%, h_{S}^{h o}=30 \%$, $h_{F}^{h o}=0 \%$ and $h_{P}^{h o}=75 \%$. Furthermore, we also take into account that due to these measures the number of contacts at work goes down also for those not in home-office. Hence, the introduction of home-office is associated with a (sector-specific) reduction of the value of $n^{w}$. Furthermore we assume that the productivity of workers is not affected if they are in home-office.

Whereas the measures discussed so far in the context of our model have no direct impact on economic activities the main focus of our analysis is on the implementation of measures where the reduction of contacts is directly related to the reduction of economic activity. To capture such measures, we consider restrictions, forced closures and regulations imposed on stores, restaurants and other business outlets. These restrictions of consumption activities are incorporated in our model by introducing sector-specific shopping probabilities $p_{k}^{s}$ such that a household goes shopping to the mall of sector $k$ in a given week only with that probability. In case the household does not go shopping the foreseen weekly consumption budget for that sector is added to the household's savings. Furthermore, there are specific requirements, such as access restrictions, that shop owners have to comply with to keep their shops open. These measures aim at a reduction of the average number of households that an individual can meet during shopping. In our model, this is reflected by reducing the number of contacts during shopping $n_{k}^{c}$.

In order to take into account broad empirical evidence that the adjustment of behavior upon the implementation of policy measures is sluggish, we assume that, when a policy affects the social contact parameters, the infection probability or the consumption activity parameter, then there is a phase-in period after the policy introduction, respectively a phase-out period after the elimination of the policy, during which the parameter values of the agents adjust from their original value to the new target.

Economic Support Policies The reduction in economic activity induced by the containment measures discussed above might lead to a substantial increase in unemployment as well as the depletion of firms' savings and potentially their bankruptcy. In order to

\footnotetext{
${ }^{11}$ In fact, recent data show that working from home has massively increased in German companies after the outbreak of COVID-19 (see Möhring et al., 2020).
} 
avoid such phenomena and resulting vicious cycles for demand and output, the government might combine the containment measures with economic support policies. We consider such policies which particularly aim at avoiding bankruptcies and strong increases in unemployment in the direct aftermath of the introduction of the containment measures. More precisely, in our analysis we consider the option to implement a combination of a short-term work scheme and a firm bailout policy. Under the short-time work scheme firms have the possibility to put workers not needed under the current production plan in short-time work. The worker, then, receives a fraction $\varphi=0.7$ of the regular wage and the firm receives this amount as a transfer from the public account. Once the firm starts expanding again, it first calls back employees from its short-time list before hiring new workers. A worker can be in the short-time work scheme for at most six months in a row. Furthermore, the bailout policy implies that for any firm with negative savings in a given period, the savings account is balanced by a transfer from the public account, thereby avoiding that the firm goes bankrupt.

Both policy measures are associated with a considerable increase in the governmental spending and, due to the mechanics of the tax rule, normally would trigger an upward adjustment of the tax rate. In order to avoid a pro-cyclical effect of taxation, the adjustment of the tax rate can be suspended as a third economic policy measure.

\section{Reproduction of Dynamics in Germany}

Before systematically analyzing all the economic and epidemiological effects of different policy measures, we first demonstrate that our calibrated model is able to reproduce German data with respect to the evolution of key economic and pandemic variables for the time window of 63 days between March 9, 2020 and May 10, 2020. A whole set of measures has been introduced in Germany shortly after the start of this time window. In particular, these measures include individual prevention measures, the introduction of home office in the majority of companies, a regulation forbidding meetings between more than two people in public spaces (with the exception of families), the closure of a large fraction of stores (apart from super-markets, and stores for food and other essential products) as well as all hotels and restaurants. In the framework of our model we put all these measures together to a single lock-down policy. As discussed above, there is a phasein period after the implementation of the policy during which the model parameters adjust to their new value. The policy implements home-office for all workers where it is possible and, based on the different fractions of worker in home-office across sectors, the number of contacts at work of those not in home-office decreases to $n^{w, l}=(4,5,8,2)$, where the first three entries refer to the three private sectors and the last entry to the public sector. Furthermore, the average number of daily private contacts is reduced by approximately $50 \%$ to $n_{y y}^{p, l}=2, n_{o o}^{p, l}=1, n_{o y}^{p, l}=1, n_{y o}^{p, l}=1 .{ }^{12}$ These numbers for the reduction of contacts is based on surveys about the change in private contacts after the introduction of measures, (see Lehrer et al., 2020), and also take into account that particular care was taken in order to reduce the number of contacts of people older than 65 years of age. Furthermore, the shopping frequency in the three sectors is reduced from the default of $p^{s}=(1,1,1)$ for all consumers before the crisis to $p^{s, l}=(0.85,0.5,1)$. These numbers are based on reports about the reduction of demand in different sectors after the introduction of the containment measures. ${ }^{13}$ Furthermore, the number of contacts during consumption activities in the

\footnotetext{
${ }^{12}$ The superscript 'l' always refers to the parameters in the lock-down stage.

${ }^{13}$ Data on the reduction in revenue in manufacturing in Germany is available here. Given the wide set of sectors included in Service obtaining concrete numbers of revenue reduction is difficult and our estimation
} 
Table 6: Default values for lock-down policy.

\begin{tabular}{lc}
\hline & lock-down \\
\hline Social distancing & $\xi=0.6$ \\
Home office & Yes \\
Work contacts & $n^{w, l}=(4,5,8,2)$ \\
Private contacts & $n_{y y}^{p, l}=2, n_{o o}^{p, l}=0.5, n_{o y}^{p, l}=1, n_{y o}^{p, l}=0.5$ \\
Shopping contacts & $n^{s, l}=(5,20,10)$ \\
Shopping frequency & $p^{s, l}=(0.85,0.5,1)$ \\
\hline Short time & Yes \\
Bailout & Yes \\
\hline
\end{tabular}

manufacturing and service sector are reduced to $n^{c, l}=(5,20,10)$. This captures an increase in online shopping and the fact that, due to the reduced shopping activity of others, agents, in any case, have fewer contacts when shopping. Furthermore, consistent with the German case and in addition to these virus containment measures, the start of the lock-down policy also implies that the government activates the bailout policy and the short-time program, as described in Section 2.5. An important role for the infection dynamics plays the parameter $\xi$ describing by how much the individual prevention measures of the policy reduces the infection probability at each meeting between a susceptible and an infectious agent. Since there is no data available to directly estimate this parameter, we calibrate it. In particular, we choose the parameter in a way such that the average number of infected at the end of the considered time window matches the empirical data as good as possible. Based on this, we set $\xi=0.6$ and throughout our analysis, if not stated differently, we assume that individual prevention measures lead to the reduction of the infection probability $p_{\text {inf }}$ by this factor. As part of our analysis, in the next section we will also consider scenarios where we assume that, due to less disciplined implementation of the individual prevention rules, their effect decreases during the opening-up stage. To capture such a scenario, we will use a smaller value of $\xi$ during the opening-up stage. Table 6 summarizes the default parameter setting for the lock-down stage underlying the simulations in this section.

In Figure 1 we show the dynamics generated by the model if this policy resembling the German measures is introduced two weeks after the appearance of the virus (corresponding to March 23, 2020). The simulation data is based on a batch of 20 runs with identical initial conditions and the blue lines in all panels show the mean across the runs whereas the standard deviation is given by the dotted black lines. In Panel (a) the simulated dynamics of the reported number of infected is compared to data from Germany for the considered time window. ${ }^{14}$ More precisely, the green line shows the number of reported cases in Germany scaled to a population of 100.000 inhabitants. This Panel displays that the empirical data is well within the confidence interval (mean plus/minus standard deviation) of the simulations and that the simulated data reproduces both the shape of the diffusion curve and the slope at the end of the considered interval. In Panel (b) the evolution of a weekly average of the estimated reproduction factor $R_{0}$ is shown. Both for the simulation and the real data this factor calculated every day as the ratio of the reported

of a reduction of $50 \%$ is based on reported numbers in different service areas.

${ }^{14}$ This data is taken from the database of the Johns Hopkins University at https://github.com/ CSSEGISandData/COVID-19 


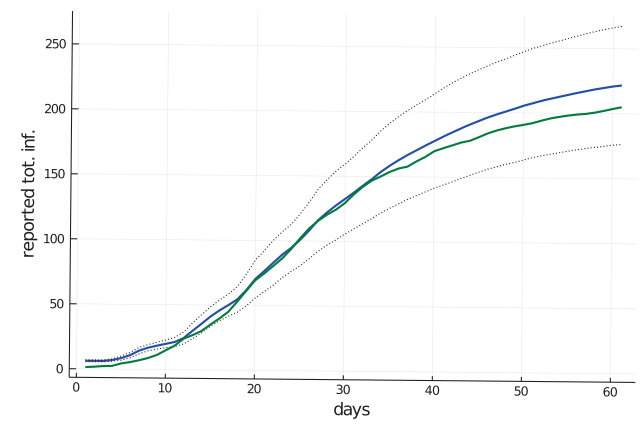

(a)

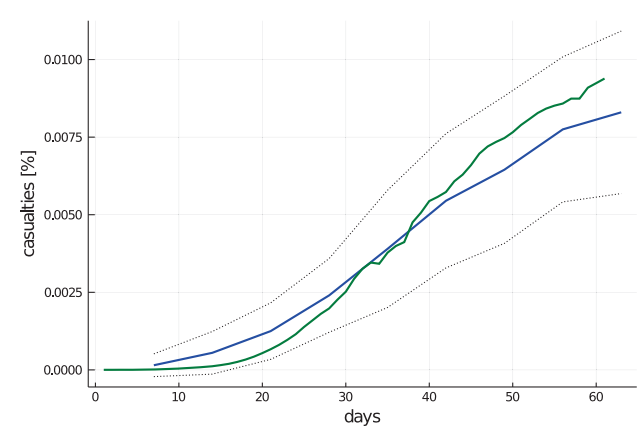

(c)

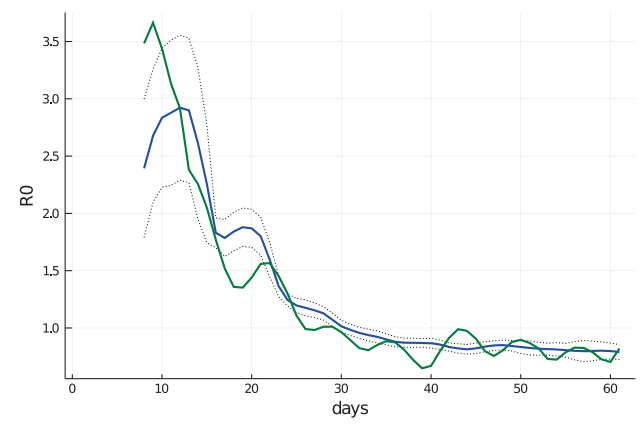

(b)

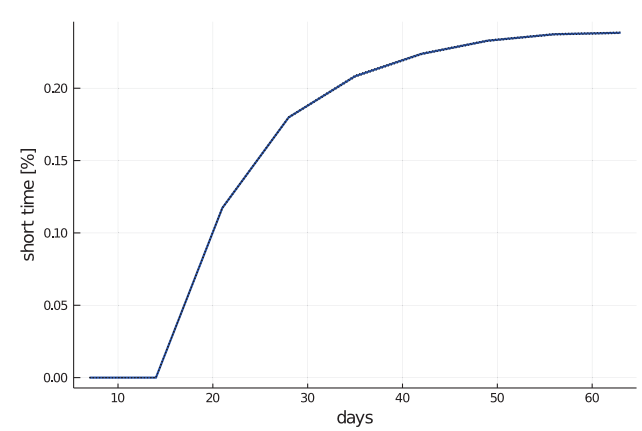

(d)

Figure 1: Comparison of empirical data (green line) and simulation results (blue line) for the dynamics of the reported number of infected (a), the smoothed $R_{0}$ value (b) and casualties as a percentage of the population (c). Panel (d) shows the simulation data for the percentage of workers in the short-time program.

newly infected during the last four days and the newly infected during the four days before that. ${ }^{15}$ Since the daily $R_{0}$ estimates are very volatile we show the dynamics of the mean of the estimated $R_{0}$ value during the last seven days. Also with respect to this indicator we can see that the simulation matches the data very well. Similarly, the dynamics of the casualties predicted by the model is a good match of the empirical data, as demonstrated in Panel (c). Panel (d) shows the dynamics of the number of workers whom their employer has put into the short-time program. Only simulation data is shown here since no time series for the empirical data is available. In order to connect this time series to empirical data we observe that, according to an announcement of the German Federal Employment Agency (see Bundesagentur für Arbeit, 2020), 10.1 million workers were reported to be in short-time work at the end of April 2020. In light of a workforce of approximately 45 million this corresponds to $22.5 \%$, which is very close to the mean of the simulation data, which gives a fraction of workers in short-time of $22.3 \%$ at day 49 , corresponding to the end of April 2020. Overall, this discussion shows that the calibrated model does not only seem to capture the effect of different policy measures on the spreading of the virus in the population, but also its economic impact. Based on the shown ability of the model to reproduce empirical dynamics, we now employ the model to explore economic and pandemic dynamics that would emerge under alternative policy responses to the outbreak

\footnotetext{
${ }^{15}$ This way of estimating $R_{0}$ is following the approach used by the Robert Koch Institute. In Appendix A.3 a detail description of the computation is available based on Robert Koch Institut (2020).
} 


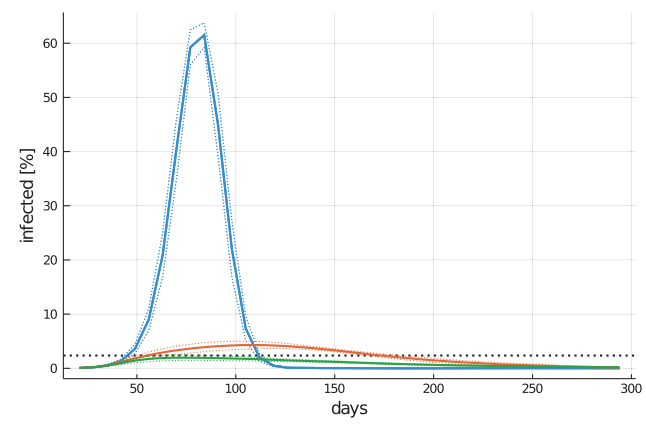

(a)

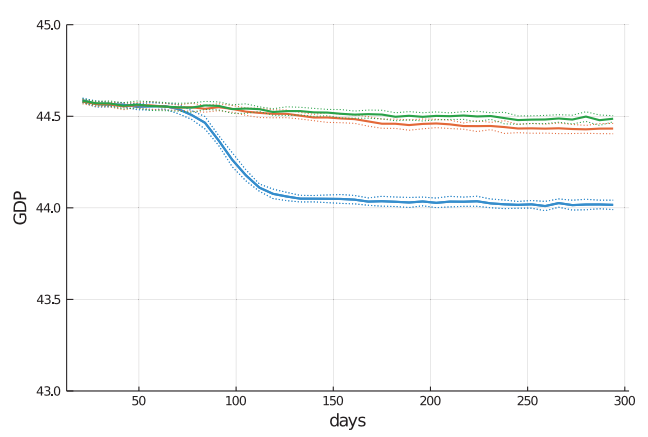

(c)

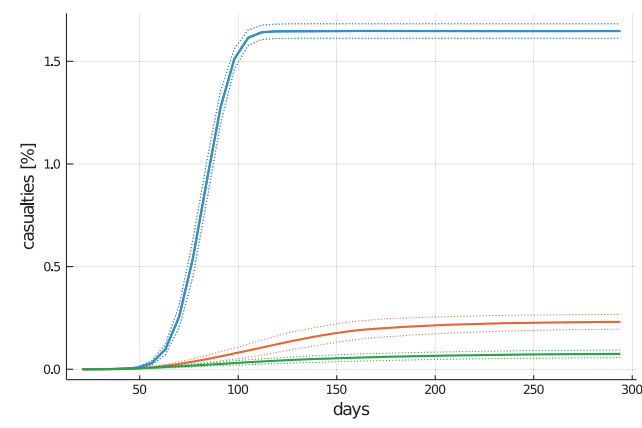

(b)

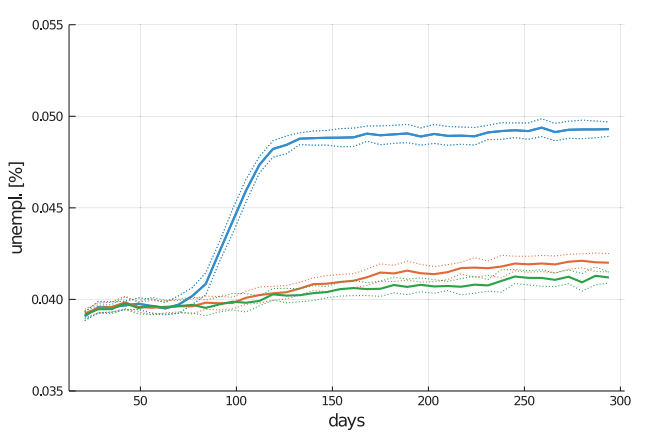

(d)

Figure 2: Dynamics of currently infected individuals (a) and total casualties (b) as well as GDP (c) and unemployment rate (d) for the scenarios with no policy measures (blue), only social distancing (red) and social distancing in combination with home office (green).

of the virus.

\section{Policy Analysis}

\subsection{Policies without direct economic impact}

As a first step of our policy analysis we examine which options a policy maker has to reduce the spreading of the virus without directly interfering with economic activities in the sense of closing stores or reducing the possibility to consume services. More precisely, we consider three policy scenarios. First, a scenario where no containment measures are taken at all. Second, the introduction of only individual prevention measures, and third the combination of these individual prevention measures with home office.

Figure 2 shows the dynamics of the percentages of the population of currently infected and of casualties. The black dotted line in Panel (a) indicates the upper bound on the number of infected under which the intensive care capacities are still not fully used. The curve of infected individuals in the absence of any measures follows a steep hump-shaped pattern well known from standard SIRD models. Due to herd immunity the virus is eliminated after approximately 120 days but the associated mortality is about $1.6 \%$. Already the introduction of the individual prevention measures strongly reduces the speed of the diffusion of the virus and the maximal number of infected. Complementing individual prevention measures with home-office reinforces these effects and average mortality can 
be reduced by a factor of approximately 10 compared to the scenario without any containment. Nevertheless, the simulations indicate that these measures are not sufficient to ensure that the number of infected stay below the intensive care capacity. Considering the GDP and unemployment dynamics shown in panels (c) and (d), it is confirmed that these measures are not associated with any direct economic costs. A crucial assumption in this respect is that, as discussed earlier, in our setting productivity of workers is not reduced when they move to home-office. The slight decrease in GDP and increase in unemployment around period 100 in this scenario without containment measures is due to the reduction in demand induced by the large mortality.

\subsection{Policies with direct economic impact}

We now consider containment policies which, apart from introducing individual prevention measures and home office, also directly induce a reduction of economic activity. To keep the analysis as simple and transparent as possible, we consider only two-stage policies with an initial 'lock-down' stage followed by an 'opening-up' stage. Individual prevention measures and home office are active in both stages. The amount of restrictions of the economic activity differ between the two stages. Similar to the approach taken in Section 3 we express such restrictions by assuming that the shopping probabilities $p_{k}^{s}, k \in\{M, S\}$ of households for the sectors manufacturing and service are reduced. The parameters $\alpha^{l}$ and $\alpha^{o}$ determine the amount of reduction of the shopping probabilities during the lock-down and the opening-up phase, where $\alpha^{l}=1$ yields values of $p^{s}$ identical to those used for the representation of the German policy in Section 3. During the lock-down also the number of contacts in case a household goes shopping and also the number of private contacts are reduced to the values already used in Section 3. These restrictions on contacts are lifted in the opening-up stage. The values of the parameters under the two policy stages are summarized in Table 7 . As a default, the policy starts two weeks after the first appearance of the infected agents with the lock-down stage. The transition from the lock-down to the opening-up stage happens when the reported number of newly infected agents during one week is below a threshold $\alpha^{\text {lo }}$. If later in the simulation the number of reported newly infected increases above $\alpha^{l o}$, then the restrictions of the lockdown stage are again activated. Once vaccination is available $t_{v a c}$ days after the outbreak of the virus, the infection probability $p_{\text {inf }}$ becomes zero and all restrictions are lifted. Our policy analysis is carried out under the assumption that a vaccine is available one year after the occurrence of the pandemic, i.e. we set $t_{v a c}=379$. The total time horizon of our analysis is 18 months, since economic implications of the measures taken extend substantially beyond the time interval in which they are applied. In the first part of this section we assume that no complementary economic support measures for firms and workers are introduced in combination with the containment policies. ${ }^{16}$ This allows us to obtain insights about the isolated economic implications of the containment policies. In the second part of this section we will then examine in how far our insights about the efficient design of containment policies change if they are complemented with economic support policies.

The policy analysis is structured in a way that we start from a default policy scenario and then systematically investigate the implications of variations of the three policy parameters. We set $\alpha^{l}=1, \alpha^{o}=0$ and $\alpha^{l o}=5$ as the default policy. The reduction in

\footnotetext{
${ }^{16}$ It should be noted that in this respect the default setup we use in the policy analysis differs from the scenario used in the previous Section 3 for the model calibration, since there, based on actual German policy choices, we have activated economic support measures together with the containment policies.
} 
Table 7: Parameter values in the lock-down and opening-up stages of the policy.

\begin{tabular}{|c|c|c|}
\hline & \multicolumn{2}{|r|}{ opening-up } \\
\hline Social distancing & \multicolumn{2}{|r|}{$\xi=0.6$} \\
\hline Home office & \multicolumn{2}{|r|}{ Yes } \\
\hline Private contacts & \multirow{2}{*}{$\begin{array}{c}n_{y y}^{p, l}=2, n_{o o}^{p, l}=0.5, n_{o y}^{p, l}=1, n_{y o}^{p, l}=0.5 \\
n^{s, l}=(5,20,10)\end{array}$} & $n_{y y}^{p, o}=5, n_{o o}^{p, o}=2, n_{o y}^{p, o}=4, n_{y o}^{p, l}=2$ \\
\hline Shopping contacts & & $n^{s, o}=(8,28,10)$ \\
\hline Shopping frequency & $p^{s}=(1,1,1)-\alpha^{l}(0.15,0.5,0)$ & $p^{s}=(1,1,1)-\alpha^{o}(0.15,0.5,0)$ \\
\hline & \multicolumn{2}{|c|}{$\begin{array}{l}\text { Table 8: Range of the key policy parameters } \\
\text { (default values or bold face). }\end{array}$} \\
\hline & \multicolumn{2}{|c|}{ Parameter Values } \\
\hline & $\alpha^{l}$ & $0.25, \quad 0.5, \quad 0.75, \quad 1, \quad 1.25$ \\
\hline & $\alpha^{o}$ & $\begin{array}{llll}\mathbf{0}, & 0.25, & 0.5, & 0.75\end{array}$ \\
\hline & \multicolumn{2}{|r|}{$\mathbf{5}, \quad 10,30,50$} \\
\hline
\end{tabular}

manufacturing and service consumption during the lock-down stage of the default policy corresponds to the level of restrictions under our German calibration, the opening-up results in the elimination of any restrictions of economic activity and the condition for activating the opening-up stage, and to keep it activated, is that during the last week there were less than 5 reported newly infected per 100.000 individuals. The choice of this threshold is such that, under the use of the default values for $\alpha^{l}$ and $\alpha^{o}$, it induces a lock-down of about 9 weeks. We choose this value because it is consistent with data in several affected countries and, as we will show below, larger values of the threshold seem to be inefficient.

In Table 8 we list the different values for the three policy parameters we consider in our analysis. To keep the exposition clean we will not discuss all possible combinations of these parameter variations, but mainly focus our attention on the variations of one parameter at a time and additionally cover a few experiments where several parameter values deviate from the default. In light of our results we believe that this is sufficient to generate a clear picture of the effects induced, on the one hand, by making the lock-down, respectively the opening-up stage, more or less restrictive, and, on the other hand, by different levels of the transition threshold $\alpha^{l o}$. Our analysis is again based on 20 batchruns for each parameter setting, and for each parameter constellation we consider not only the dynamics of different key variables but also aggregate indicators for the economic and epidemiological effects of the considered policy. As an indicator for the economic costs we consider the average GDP-loss in the 18 months after the outbreak of the virus. The loss is expressed as a percentage of the GDP level prior to the outbreak of the virus. The impact of the policy with respect to the effect of the virus is measured by the total mortality during the outbreak, i.e. the total number of casualties caused by the virus until the end of the run as a percentage of the population.

Figure 3 shows the average GDP loss and virus mortality for different policy variations. Each point depicts the mean of the values of the two indicators across the 20 batch runs. In Appendix B we provide statistical tests for the significance of the difference of each indicator for the four labeled parameter combinations in the figure. The default policy scenario is labeled with 'A'. The red solid line indicates the effects of a variation of the severity of restrictions in the lock-down stage with point ' $\mathrm{B}$ ' denoting the scenario with the 


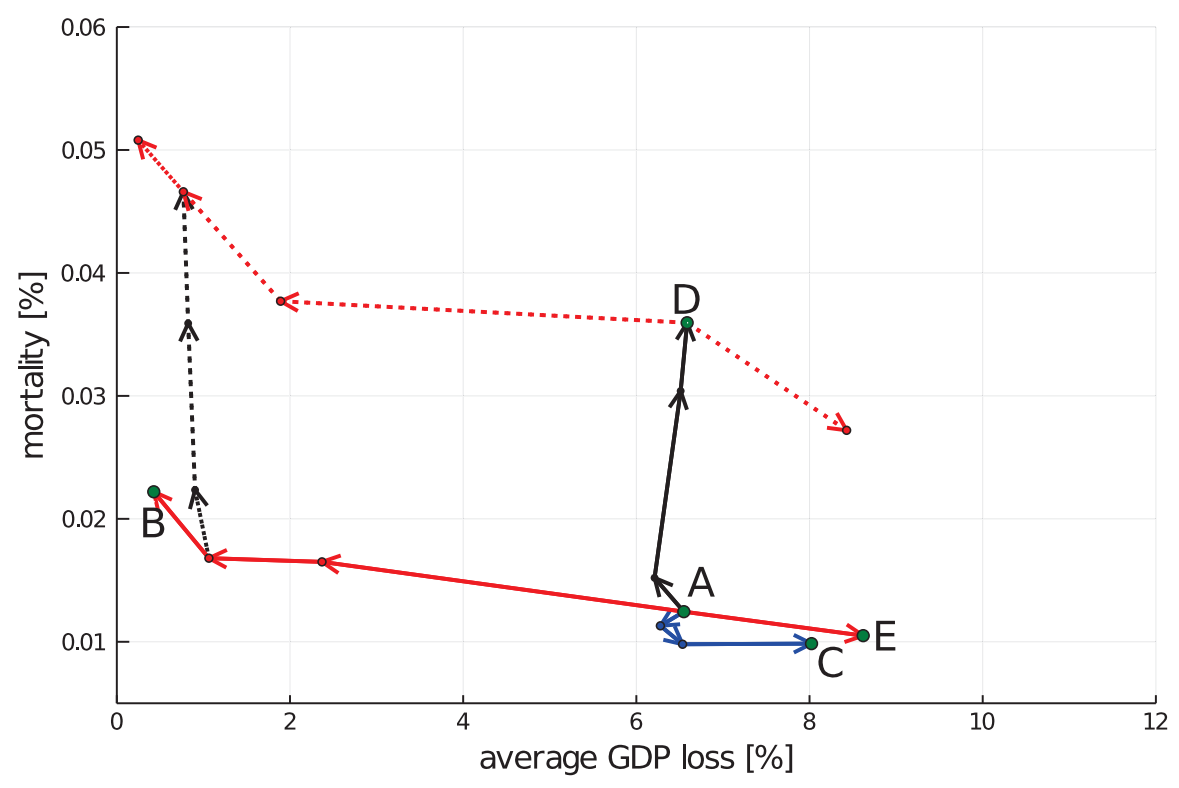

Figure 3: Effects of variations of the key policy parameters.

weakest restrictions $\left(\alpha^{l}=0.25\right)$ and point ' $\mathrm{E}$ ' to those with the strongest one $\left(\alpha^{l}=1.25\right)$. Similarly, the blue line indicates the effects of more restrictions during the opening-up stage with point ' $\mathrm{C}$ ' labeling the scenario where even after the opening-up restrictions are almost as severe as under the lock-down $\left(\alpha^{o}=0.75\right)$. Finally, the black line corresponds to a variation of the threshold determining when to switch from the lock-down to the opening-up stage and vice versa. Point ' $\mathrm{D}$ ' corresponds to a threshold of $\alpha^{l o}=50$. The dotted red and black lines correspond to the solid lines of the same color, however they were calculated for $\alpha^{l o}=50$ (red dotted line) respectively $\alpha^{l}=0.5$ (black dotted line).

The figure shows that both indicators exhibit substantial variation across the set of considered policies. The mortality rate varies between approximately $0.01 \%$ and $0.05 \%$, whereas the average GDP loss is between $0.5 \%$ and $9 \%$. Several important conclusions can be drawn from this figure. First, an increase of the switching threshold above the default value of $\alpha^{l o}=5$ leads to a worsening of both considered indicators and therefore is clearly inefficient. Second, policies inducing restrictions of the consumption activities also during the opening-up stage, i.e. $\alpha^{o}>0$, either have insignificant effects $\left(\alpha^{o}=0.25,0.5\right)$ or lead to larger GDP losses without reducing mortality in a significant way $\left(\alpha^{\circ}=0.75\right.$, see Appendix B). Third, there is an efficiency frontier, the red line between the points $\mathrm{B}$ and $\mathrm{A}$, exhibiting a trade-off between reducing economic losses and inducing a higher mortality. ${ }^{17}$ The crucial factor determining the position on this frontier is the amount of reduction of consumption activities during the lock-down stage. Making the lock-down even stronger, i.e. moving from point $\mathrm{A}$ to point $\mathrm{E}$ leads to a significant increase in the GDP loss, whereas the induced reduction in mortality is insignificant (see Appendix B).

To get a better understanding of the mechanisms underlying these results, we show in Figure 4 the dynamics of key variables under the policies corresponding to points A, B, C and D from Figure 3. Panel (a) shows that weaker restrictions under the lockdown $\left(\alpha^{l}=0.25\right)$ lead both to a larger maximal number of infected individuals and a

\footnotetext{
${ }^{17}$ Our notion of an efficiency frontier here refers only to the interplay of our two indicators GDP-loss and mortality and is not connected to notions like Pareto-efficiency in the model.
} 
Table 9: Comparison of policy results.

\begin{tabular}{ccccc}
\hline & $\begin{array}{c}\mathrm{A} \\
(\text { default })\end{array}$ & $\begin{array}{c}\mathrm{B} \\
\left(\alpha^{l}=0.25\right)\end{array}$ & $\begin{array}{c}\mathrm{C} \\
\left(\alpha^{o}=0.75\right)\end{array}$ & $\begin{array}{c}\mathrm{D} \\
\left(\alpha^{l o}=50\right)\end{array}$ \\
\hline GDP loss [\%] & $6.55(0.94)$ & $0.43(0.11)$ & $8.0(0.18)$ & $6.56(0.32)$ \\
Mortality [\%] & $0.012(0.0043)$ & $0.022(0.0085)$ & $0.01(0.0036)$ & $0.036(0.011)$ \\
Duration Lock-down & $86.87(76.49)$ & $120.75(21.41)$ & $57.4(10.05)$ & $16.45(4.11)$ \\
Switch Opening/Lock-down & $0.8(1.11)$ & $1.3(1.38)$ & $0.05(0.22)$ & $0.03(0.47)$ \\
Pub. Acc. Deficit [\%] & $2.60(1.0)$ & $0.67(0.01)$ & $3.4(0.33)$ & $0.7(0.17)$ \\
\hline
\end{tabular}

substantially higher persistency of the virus in the population compared to the default policy. On the other hand, the GDP loss under this policy builds up more slowly than under the default policy. Although under this policy the lock-down phase lasts by far the longest (see Table 9), GDP returns to values close to the pre-policy level after about 200 days, such that the duration of GDP loss is less than half of that for the three other policies (Panel (b)). On the other hand this policy induces the risk of repeated returns to the lock-down phase, which is much less likely under the other three policies (see Table 9 ). With respect to a policy with a more cautious opening-up stage $\left(\alpha^{o}=0.75\right)$, Figure 4 confirms that the implications for the infection dynamics are almost identical to that of the default policy. However, Panel (b) shows that, under such a restrictive opening-up stage, the economy temporarily converges to a stationary GDP level which is clearly below the pre-crisis level and only returns to the original level after all constraints are lifted given vaccination availability. Finally, under a high threshold for opening up $\left(\alpha^{l o}=50\right)$, the lock-down phase is finished very early (see Table 9) and the number of infected decreases only slowly afterwards, see Figure 4(a). With respect to GDP loss, the earlier lifting of the lock-down does not imply an improvement compared to the default policy. Figure 4(b) indicates that a longer lock-down actually induces higher output after the recovery from the crisis. The reason for this observation is that the lock down and the associated reduction in demand induces bankruptcies primarily of the less productive firms and, due to the intensified competition, an increase in market shares of the most productive ones. This reallocation of market shares remains effective also after the full recovery of the economy lifting the post crisis GDP slightly above the pre-crisis level. No such effect occurs under a weak (policy B) or a short (policy D) lock-down. Furthermore there is a substantial difference between the policies with respect to the deficit they generate in the public account. The last row in Table 9 shows the increase in the public deficit after 18 months as a percentage of the pre-crisis annual GDP. The default policy (A) generates a substantially higher deficit compared to both a longer, weaker lock-down (B) and a policy with a higher lock-down threshold (D). Having only a weak opening-up (C) generates a large public deficit, quite consistent with the observation that it generates a large GDP loss. Overall, also the consideration of the public deficit does not alter our main conclusion that a weak opening up or a large threshold for triggering the opening-up are not in the set of efficient policies.

The main messages of the first part of our policy analysis are twofold. First, an efficient policy should have a low switching threshold combined with a full relaxation of restrictions of consumption activity in the opening-up stage. Second, the amount of reduction of economic activity during the lock-down induced by the policy gives rise to a trade-off between economic costs (GDP loss and public deficit) and the mortality of the virus, i.e. a movement along the frontier between $\mathrm{B}$ and $\mathrm{A}$ in Figure 3. 


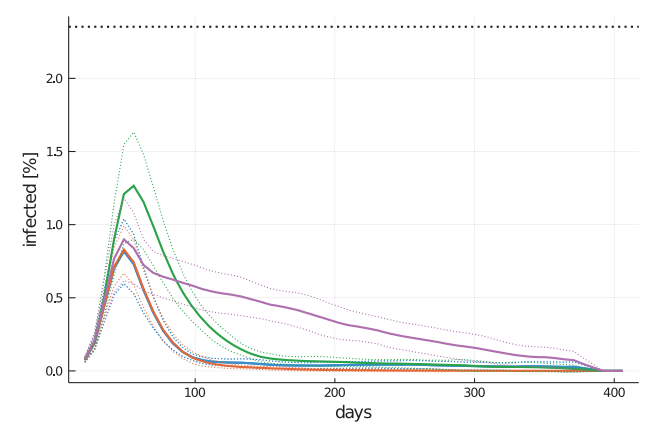

(a)

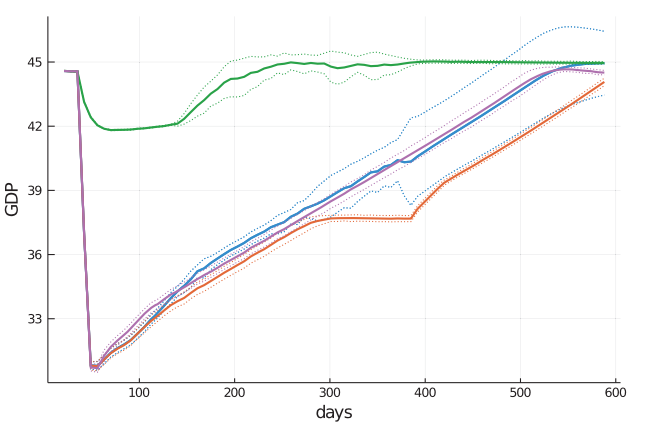

(b)

Figure 4: Dynamics of currenlty infected individuals (a) and GDP (b) for the default policy (blue), $\alpha^{l}=0.25$ (green), $\alpha^{o}=0.75$ (red) and $\alpha^{l o}=50$ (purple).

Effects of an increase in the infection probability in the opening-up stage Our analysis so far has assumed that the opening-up increases economic activity and the number of contacts of the agents, but that the effect of the individual prevention measures remain unchanged, i.e. the factor, by which the infection probability at each meeting is reduced due to the measures taken, is $\xi=0.6$ both during the lock-down and the opening -up stage. Arguably, the fact that different measures are relaxed once the opening-up stage starts might induce that part of the population reduces also the care with which the individual prevention measures are followed, thereby reducing their effect. To check in how far our insights about the efficient policy design obtained above are robust with respect to such unintended effects of the opening-up, we repeat here our analysis from above and vary the key policy parameters in the ranges given in Table 8 , but assume that the social distancing parameter $\xi$ during the opening-up stage is only $\xi^{o}=0.5$, whereas it remains at the default value $\xi^{l}=0.6$ during the lock-down.

Figure 5 shows that this relatively small increase in the virus transmission probability at a meeting between a susceptible and an infected during the opening-up stage changes several aspects of the effects of the different policy parameters. Comparing this figure to the corresponding Figure 3 for our standard scenario shows that the mortality and the GPD loss are higher relative to the previously considered setting. The insights about the inefficiency of a large threshold $\alpha^{l o}$ and also about the trade-off associated with inducing less restrictions during the lock-down (i.e. choosing a lower $\alpha^{l}$ ) still apply in this setting. However, increasing the threshold to $\alpha^{l o}$ now has a much stronger mortality-increasing effect. ${ }^{18}$ A qualitative difference arises with respect to the choice of the parameter $\alpha^{o}$ determining the restrictions during the opening-up stage. Differently from the standard case, a more cautious opening-up seems more efficient in a scenario where the social distancing effects decline during the opening-up. More precisely, choosing $\alpha^{o}=0.75$ seems to reduce mortality, although the effect, like in the default scenario, is not statistically significant, but contrary to the default scenario does so without inducing any additional GDP loss compared to full opening. Combinations of such a restrictive opening-up stage with different lock-down intensities now gives rise to a new efficiency frontier (the red dotted line in Figure 5). Efficient policy choices now either combine a weak lock-down with a full opening-up or a restrictive lock-down with a very cautious opening-up stage.

\footnotetext{
${ }^{18}$ The policy ' $\mathrm{D}$ ' with $\alpha^{l o}=50$ generates such high average mortality of approximately 0.09 that it is outside the range depicted in Figure 5.
} 


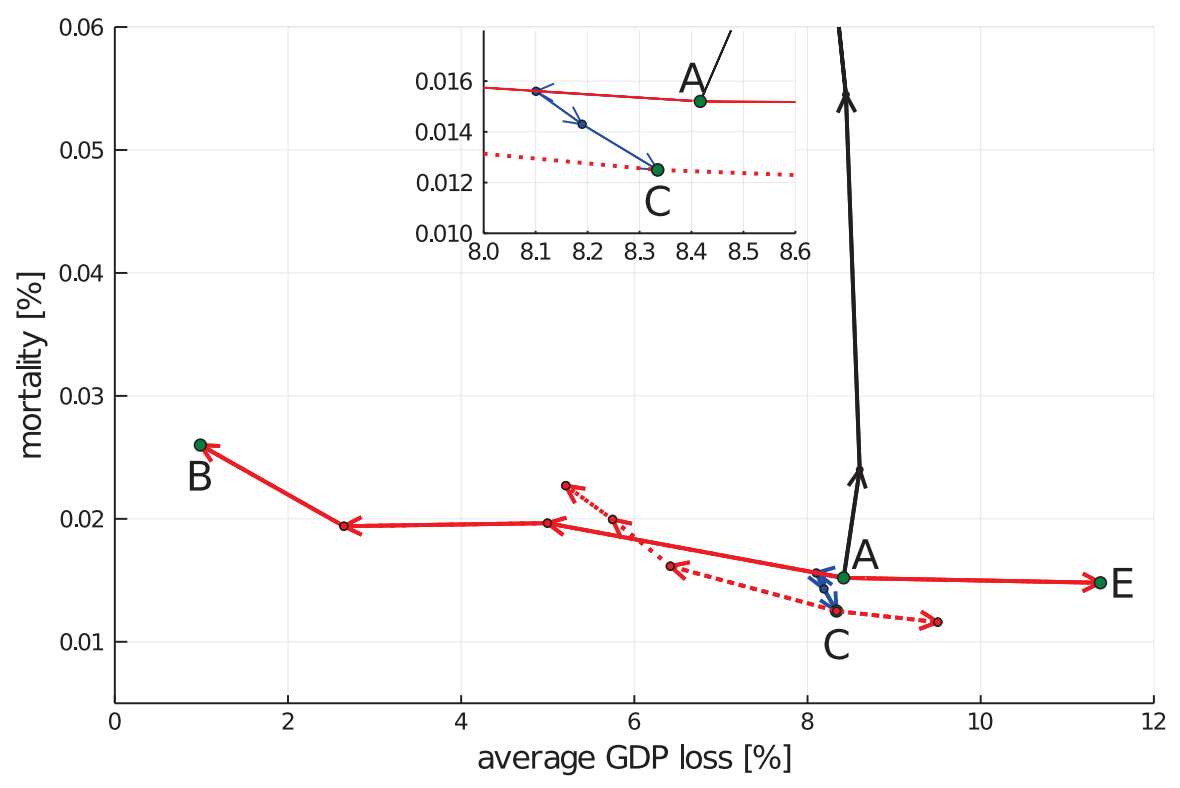

Figure 5: Effects of variations of the key policy parameters with $\xi^{o}=0.5$.

The dynamics of infections and GDP loss for different policies under this scenario is depicted in Figure 6. Panel (a) of the figure clearly shows that in case of a loosening up of individual prevention measures during the opening-up stage an almost constant positive stock of infected emerges under all policies except the weak opening-up policy C. Under a large threshold $\alpha^{l o}=50$ the stock of infected is substantially larger compared to the three other policies. Considering the dynamics of the GDP loss in Figure 6(b) and the numbers reported in Table 10 shows that, with the exception of the weak opening policy, there are numerous switches back to the lock-down stage and, under the default policy (A) and the weak lock-down policy (B), the economy is under lock-down for a very extensive time period. Under the more cautious opening-up policy $(\mathrm{C})$ the total duration of the lock-down is much smaller and, in spite of this, mortality is lower than under the default policy. As can be seen in Figure 6(b), due to the long periods under lock-down, the GDP loss under the default policy is very close to that under policy $\mathrm{C}$ with the more cautious opening. Hence, in this scenario the cautious opening-up policy is indeed more efficient than the default. The implications of a large threshold $\alpha^{l o}$ are even more detrimental in this scenario with less reduction of the individual infection probabilities during the opening-up stage than in the benchmark considered above. The reason is that the constant large stock of infected generates a high mortality, while even the large threshold cannot avoid additional lock-downs such that the GDP dynamics (see Figure 6 (b)) and the total GDP loss is close to that for policies with smaller thresholds.

The costs of a late policy response Apart from deciding about the exact nature of the measures to fight the dissemination of the virus, a policy maker also has to decide when to introduce such measures. Throughout our analysis so far we have assumed that any policy is introduced two weeks after the first infected appear in our population. ${ }^{19}$ Considering

\footnotetext{
${ }^{19}$ Since in our model we start the spreading of the virus by infecting a whole set of agents, namely 0.01 percent of the population, this point in time should not be mixed up with the infection of the first individual in the entire population.
} 


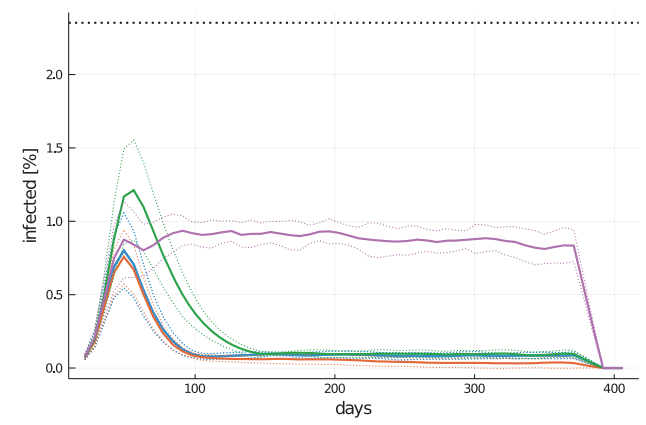

(a)

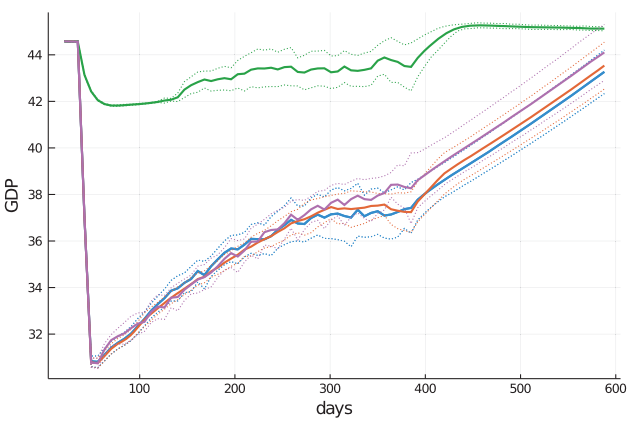

(b)

Figure 6: Dynamics of currently infected individuals (a) and GDP (b) for the default policy (blue), $\alpha^{l}=0.25$ (green), $\alpha^{o}=0.75$ (red) and $\alpha^{l o}=50$ (purple) in a scenario with $\xi^{l}=0.6, \xi^{o}=0.5$.

Table 10: Comparison of policy results with $\xi^{l}=0.6, \xi^{o}=0.5$.

\begin{tabular}{ccccc}
\hline & $\begin{array}{c}\mathrm{A} \\
\text { (default) }\end{array}$ & $\begin{array}{c}\mathrm{B} \\
\left(\alpha^{l}=0.25\right)\end{array}$ & $\begin{array}{c}\mathrm{C} \\
\left(\alpha^{o}=0.75\right)\end{array}$ & $\begin{array}{c}\mathrm{D} \\
\left(\alpha^{l o}=50\right)\end{array}$ \\
\hline GDP loss [\%] & $8.42(0.40)$ & $0.99(0.16)$ & $8.33(0.50)$ & $7.93(0.57)$ \\
Mortality [\%] & $0.015(0.0055)$ & $0.026(0.0076)$ & $0.012(0.0039)$ & $0.089(0.0086)$ \\
Duration Lock-down & $158.55(76.45)$ & $320.6(117.83)$ & $93.1(70.74)$ & $109.9(81.48)$ \\
Switch Opening/Lock-down & $7.55(1.76)$ & $6.9(1.83)$ & $1.75(1.62)$ & $8.7(0.86)$ \\
Pub. Acc. Deficit [\%] & $4.54(0.51)$ & $0.96(0.12)$ & $3.72(0.52)$ & $2.40(0.52)$ \\
\hline
\end{tabular}

the policy responses of different countries to the outbreak of the COVID-19 pandemic, however, substantial heterogeneity in the timing of the introduction of different measures could be observed. Intuitively, concerns about the potential damage for the economy might be invoked in order to argue in favor of delaying strong lock-down measures. To address this issue we list in Table 11 average mortality and GDP loss under the default policy (and our standard assumption that $\xi^{l}=\xi^{o}=0.6$ ) if the lock-down is introduced between 1 and 4 weeks after the first occurrence of infected agents.

The results clearly indicate that delaying the policy response is quite costly in terms of the resulting mortality of the pandemic, with an increase of mortality by a factor of about 20 if the response starts 4 weeks rather than 1 week after the appearance of the virus. The difference in economic costs is however neglibible, although a later start of the policy leads

Table 11: Effects of different policy starting dates

\begin{tabular}{ccccc}
\hline & 1 week & 2 weeks & 3 weeks & 4 weeks \\
\hline GDP loss [\%] & $6.43(0.76)$ & $6.55(0.94)$ & $6.09(0.35)$ & $6.29(0.27)$ \\
Mortality [\%] & $0.007(0.0026)$ & $0.012(0.0043)$ & $0.030(0.0077)$ & $0.138(0.0406)$ \\
Duration Lock-down & $72.45(12.9)$ & $86.45(76.49)$ & $94.5(5.79)$ & $99.4(4.87)$ \\
Switch Opening/Lock-down & $0.9(1.29)$ & $0.8(1.11)$ & $0.1(0.49)$ & $0.1(0.31)$ \\
Pub. Acc. Deficit [\%] & $2.07(0.73)$ & $2.59(1.03)$ & $2.97(0.28)$ & $3.33(0.23)$ \\
\hline
\end{tabular}


Table 12: Effects of different duration of the bailout and short-time work policy

\begin{tabular}{ccccc}
\hline & no policy & 6 months & 12 months & 18 months \\
\hline GDP loss [\%] & $6.55(0.94)$ & $3.08(1.04)$ & $3.16(0.64)$ & $2.95(0.54)$ \\
Pub. Acc. Deficit [\%] & $2.59(1.03)$ & $1.70(0.62)$ & $1.70(0.30)$ & $1.88(0.25)$ \\
\hline
\end{tabular}

to a longer duration of the lock-down (see Table 11). ${ }^{20}$ This result is consistent with the observation that the crucial driver of the cost is the large increase of unemployment and the bankruptcy wave which emerges directly after the start of the lock-down. Economic costs are generated to a large extent by the slow recovery after this initial shock, such that the actual duration of the lock-down is of minor importance. The generated public account deficit however reacts to the differences in the duration in the lock-down and is substantially larger if the policy response starts only after 4 weeks compared to the case where measures are introduced after 1 week.

Public policies supporting firms and workers Part of the economic cost induced by the virus containment policies stem from a reduction in demand triggered by the large increase in unemployment and as well as by a sizable bankruptcy wave. In our standard setting we assume that there are no public policies in place to support firms during the crisis and that firms hire and fire workers immediately according to their current labor demand. Under these assumptions our default policy induces an unemployment peak at more than $35 \%$ and approximately $35 \%$ of all firms (the majority of these firms are in the service sector) go bankrupt during the 18 months after the virus outbreak, where most of the bankruptcies happen shortly after the start of the lock-down. In this subsection we examine in how far policy measures providing public transfers in order to prevent bankruptcies and mass unemployment are able to reduce the GDP losses associated with containment policies. More precisely, we consider a combination of a bailout and a shorttime work policy, as explained in detail in Section 2.5.

Table 12 compares the GDP loss and the public account deficit for different values for the duration of this policy. In all cases the policy is started together with the default containment policy two weeks after the initial emergence of the virus. A clear message of this table is that the bailout and short-time work policy strongly reduces the GDP loss to about one third of the value observed without such economic support policy, while at the same time generating a reduction in the generated public deficit. This effect can be produced by a policy which is active only for the first six months after the introduction of the containment measure. Comparing the dynamics of the GDP with and without such policy (not depicted here) shows that the main positive effect of the policy is the reduction of the sharp demand loss directly after the introduction of the containment policy. This implies that the recovery, once the lock-down is lifted, starts from a larger GDP level and the return to the pre-crisis level of economic activity is achieved substantially earlier than in the absence of the policy. Furthermore, economic support policies also increase the speed of GDP growth during the recovery phase after the lock-down measures have been lifted. Bankruptcies during the 18 months period are reduced to less than one third of the the value without economic support policies and also the number of workers in short-time peak at less than $25 \%$ which is significantly lower than the unemployment rate peak in the absence of support measures. The lower expenditures for unemployment benefits and

\footnotetext{
${ }^{20}$ In addition to the GDP loss reported here we have also checked that number of bankruptcies does not vary significantly between the scenarios with different delays in the policy response.
} 


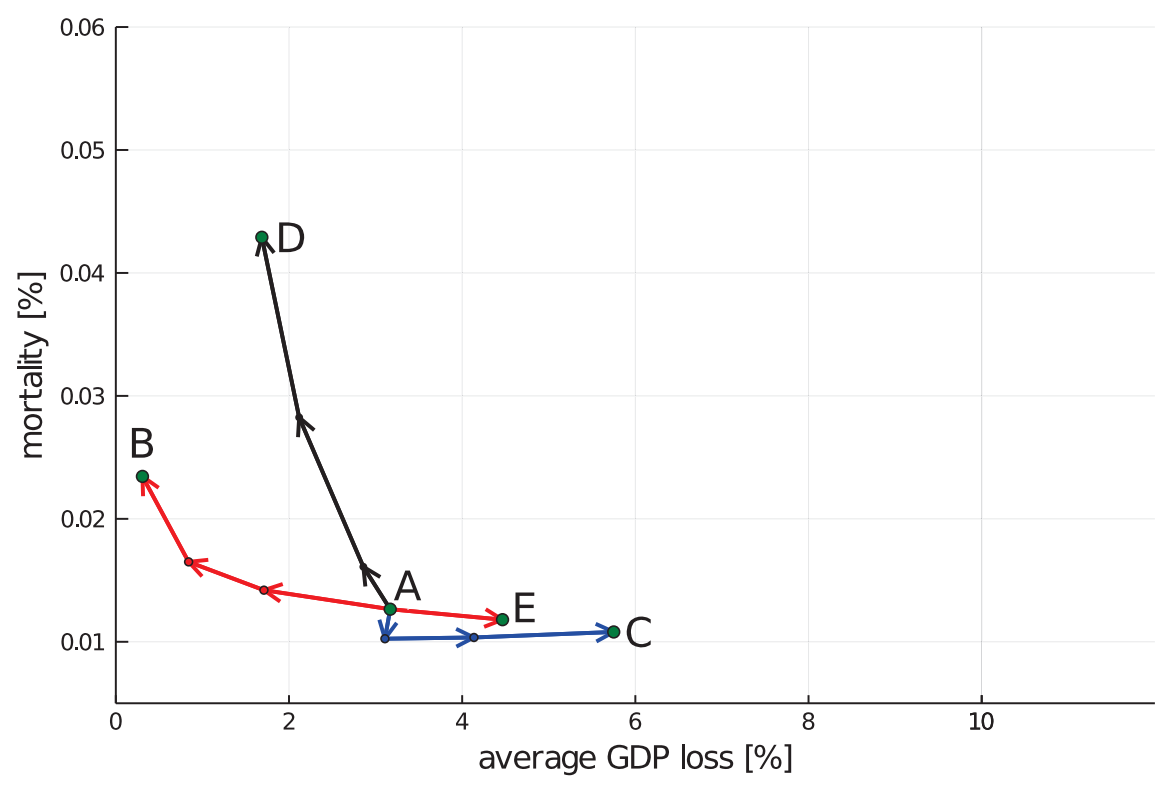

Figure 7: Effects of variations of the key policy parameters if containment policies are complemented with economic support policies.

higher tax revenues induced by the policy outweigh its direct costs also with respect to public spending, such that the deficit generated after 18 months is actually lower than under the default policy. We abstain from analyzing any additional publicly financed economic stimulus measures here, since this is not the main focus of the paper and also the effects of such policies in general will exceed the direct recovery phase of 18 months we are considering here.

Having shown the merit of complementing containment policies with economic support policies we conclude our general policy analysis by showing that our qualitative insights about the efficient design of containment policies also stay intact if these policies are implemented together with the economic support measures we have just discussed. Figure 7 shows the effect of a variation of the key parameters $\alpha^{l}, \alpha^{o}$ and $\alpha^{l o}$ in a scenario where bailout and short-time work policies are in place and otherwise the default parameters hold, in particular $\xi^{l}=\xi^{o}=0.6$. This figure corresponds exactly to Figure 3 with the only difference of the economic support measures. Comparing the two figures shows that the strong reduction in GDP loss due to the economic support policies is realized regardless of the chosen containment policy. Also, the way the two key indicators mortality and GDP loss are affected by changes in each of the three containment policy parameters does not change significantly due to the introduction of economic support measures. The efficiency frontier is still generated by the variation in the severity of the lock-down $\left(\alpha^{l}\right)$. Having a low threshold for ending the lock-down and a full opening-up afterwards is also efficient in this setting. Actually, the economic costs generated by policies with weaker opening are amplified in the presence of economic support policies. The robustness of our insights about the design of effective containment polices with respect to this variation of the economic environment suggest that these insights should also carry over to other fiscal policy settings. 


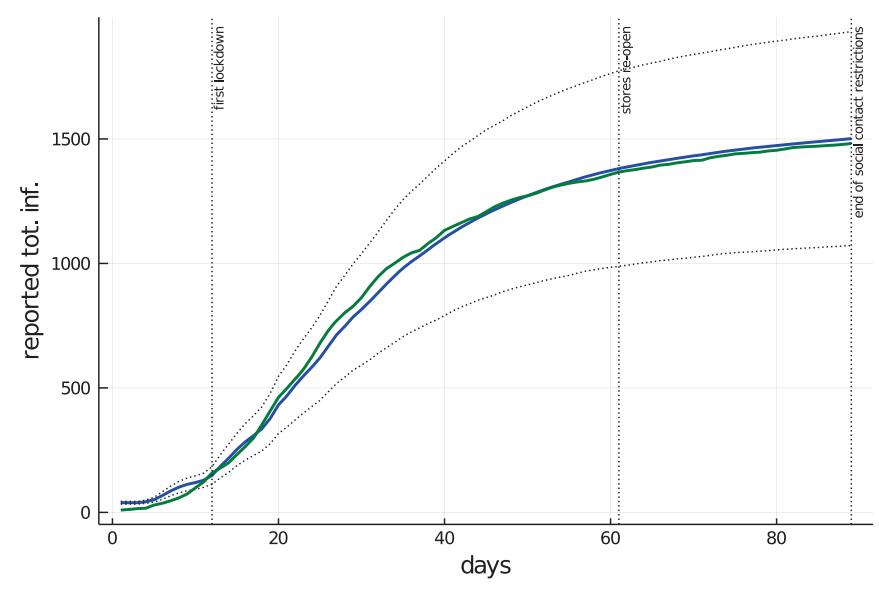

Figure 8: Comparison of empirical data (green line) and simulation results (blue line) for the infection dynamics in a two-step exit from a longer lock-down period.

\section{Two-Step Exit from a longer lock-down: The German case}

So far, we analyzed how the optimal adaptive policy would look like, if it was introduced shortly after the first infection has occurred. In many countries, including Germany, the initial policy response to COVID-19, however, was a strict lock-down for a period of at least several weeks. In Germany, most stores have been closed on March 17, 2020, followed by strict contact restrictions on March 22, 2020. The strict lock-down policy ended on May 6, 2020, when most stores reopened. Most contact restrictions were eventually repealed on June 5. The German government officially announced an adaptive policy that would reimplement a lock-down if the number of newly infected individuals exceeds a threshold of 50 per week. Compared to the general analysis in Section 4, there are two major differences: i) The lock-down policy stayed in place for an extensive period of time (80 days in total), without considering an early exit. ii) The exit is a two-step process, in which opening of stores and removal of contact restrictions do not coincide. In this section, we analyze the situation in Germany and examine which strategies should be employed after an extensive lock-down period. In contrast to Section 4, policy makers now face the question, if, when and how a second lock-down has to be initiated. Resembling the situation in Germany, in the following we assume that the initial lock-down period starts three weeks after the virus outbreak and stays in place for seven weeks. After seven weeks, all shops are reopened and after additional four weeks, all contact restrictions are removed. Thereafter, we introduce an adaptive policy, where a new lock-down is initiated, if the number of newly infected agents during a week rises above the threshold $\alpha^{l o}$, and terminated once it raises above that value.

Before proceeding to our policy analysis, we demonstrate that our model is capable of reproducing infection dynamics in Germany, also for the case of a longer lock-down period and a two-step exit. Figure 8 shows the simulation results for the setup described above and the empirical data for Germany. We use the standard calibration from Section 2.4. Without any re-calibration, our model is able to capture infection dynamics in Germany for the case of a longer lock-down and two-step exit.

We consider variations in the policy parameters $\alpha^{l o}$ and $\alpha^{o}$. Since we assume that there will be no change in the lock-down policy after it has been active for an extensive period of time, we do not consider any deviation from the default value for $\alpha^{l}$. For the first part 


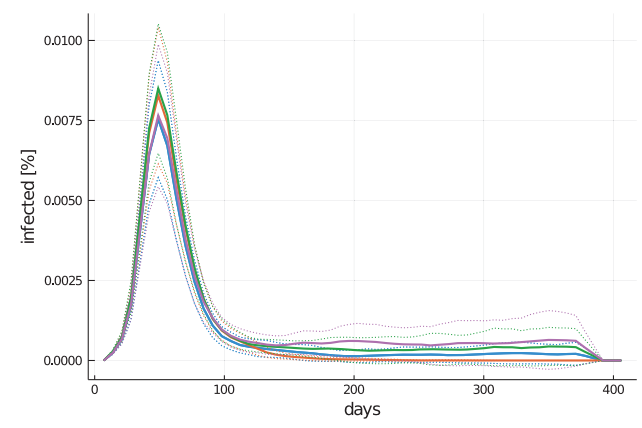

(a)

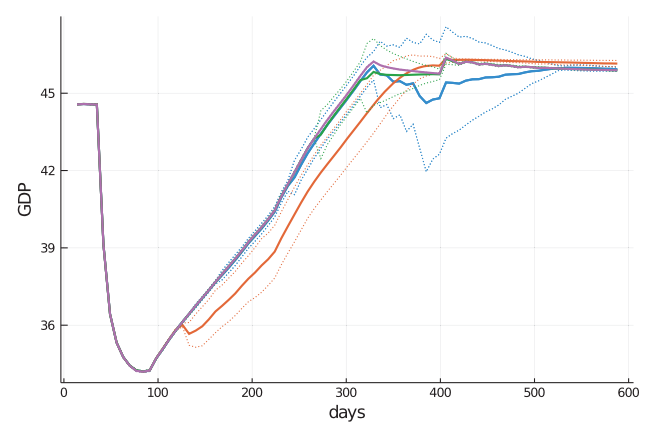

(b)

Figure 9: Dynamics of currently infected individuals (a) and GDP (b) in exit scenario for the default policy $\alpha^{l o}=5$ (blue), $\alpha^{l o}=1$ (red), $\alpha^{l o}=10$ (green) and $\alpha^{l o}=50$ (purple).

Table 13: Comparison of policy results (exit scenario, variation of $\alpha^{l o}$ ).

\begin{tabular}{ccccc}
\hline & $\alpha^{l o}=1$ & $\alpha^{l o}=5$ & $\alpha^{l o}=10$ & $\alpha^{l o}=50$ \\
\hline GDP loss [\%] & $2.93(0.43)$ & $2.6(0.52)$ & $2.41(0.16)$ & $2.35(0.02)$ \\
Mortality [\%] & $0.0102(0.0034)$ & $0.0105(0.0043)$ & $0.0134(0.0071)$ & $0.0122(0.0059)$ \\
Duration Lock-down [add'l days] & $24.85(14.45)$ & $24.5(69.58)$ & $0.7(2.15)$ & $0.0(0.0)$ \\
Switch Opening/Lock-down & $1.5(0.76)$ & $0.4(0.75)$ & $0.1(0.31)$ & $0.0(0.0)$ \\
Pub. Acc. Deficit [\%] & $2.9(0.47)$ & $2.31(0.27)$ & $2.19(0.03)$ & $2.18(0.01)$ \\
\hline
\end{tabular}

of this analysis, we again assume that the reduction of the infection probability is not affected by opening-up the economy $\left(\xi^{o}=0.6\right)$. From now on, we activate the short-time work scheme and government bailout program, since the German government introduced such measures to cope with the economic consequences of the pandemic.

Exit without increase in the infection probability in the opening-up stage Panel (a) in Figure 9 shows the dynamics of currently infected individuals for the exit scenario with full opening of stores $\left(\alpha^{o}=0\right)$ and different threshold values $\alpha^{l o}$. There is no significant difference in the dynamics between runs with different values of $\alpha^{l o}$. This can be explained by looking at the number of switches between the two policies and the additional number of days in lock-down after all restrictions have been lifted for the first time (Table 13). Independent from the threshold, we find that the economy almost never goes back into lock-down after this point in time. Only for a very low threshold of $\alpha^{l o}=1$, we consistently observe a reintroduction of the lock-down policy. For any $\alpha^{l o} \geq 5$, a switch back to the lock-down is unlikely. After 11 weeks of lock-down, with numbers of newly infected already declining, the virus is sufficiently under control and will be extinct regardless of the threshold. Hence, unless set to very low values, the threshold $\alpha^{l o}$ does not influence infection dynamics in a significant way. Similar infection dynamics result in similar number of casualties. The mortality for the exit scenario takes values between $0.01 \%$ and $0.013 \%$ and is in a similar range, compared to the default policy from Section 4. There is no significant difference in terms of mortality between different values of $\alpha^{l o}$ (see Appendix B).

Panel (b) in Figure 9 shows the GDP dynamics and Table 13 the corresponding average values of GDP loss for different threshold parameters $\alpha^{l o}$. For $\alpha^{l o}=5, \alpha^{l o}=10$ and $\alpha^{l o}=$ 


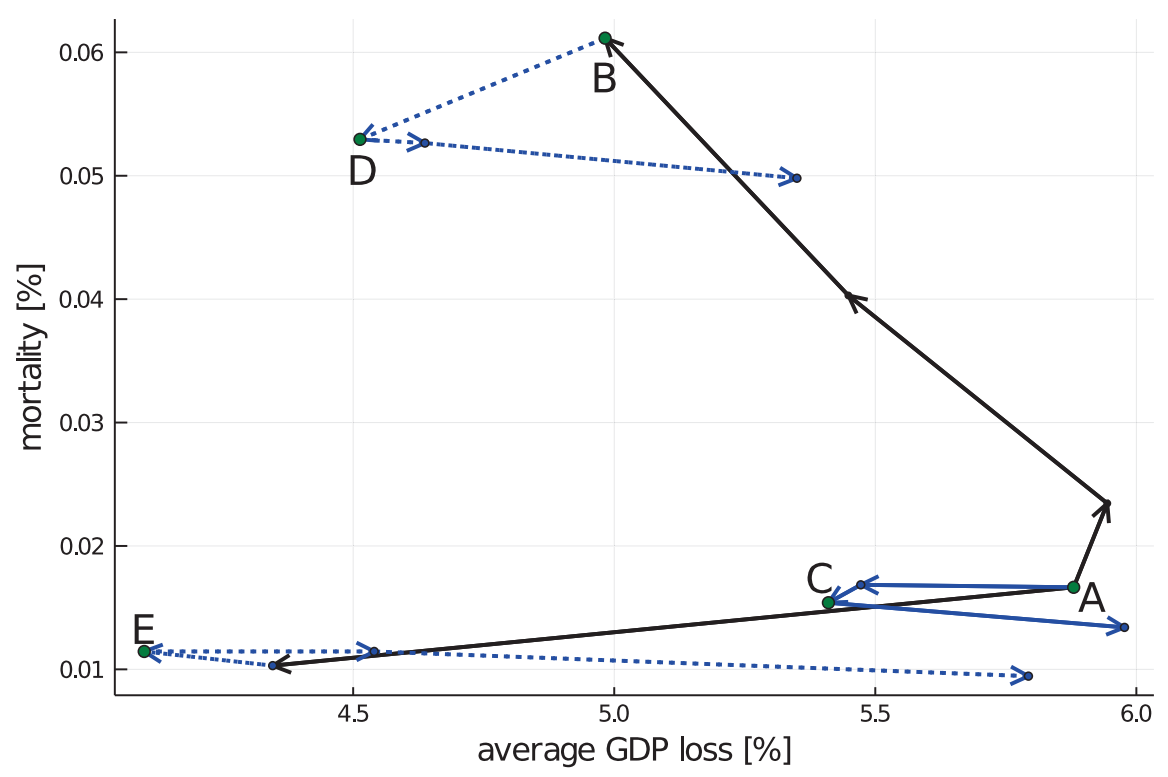

Figure 10: Effects of variations of the policy parameters $\alpha^{l o}$ and $\alpha^{o}$.

Table 14: Comparison of policy results (exit with with $\xi^{l}=0.6, \xi^{o}=0.5$ ).

\begin{tabular}{cccccc}
\hline & $\mathrm{A}$ & $\mathrm{B}$ & $\mathrm{C}$ & $\mathrm{D}$ & $\mathrm{E}$ \\
& $\begin{array}{c}\alpha^{l o}=5 \\
\alpha^{o}=0.0\end{array}$ & $\begin{array}{c}\alpha^{l o}=50 \\
\alpha^{o}=0.0\end{array}$ & $\begin{array}{c}\alpha^{l o}=5 \\
\alpha^{o}=0.5\end{array}$ & $\begin{array}{c}\alpha^{l o}=50 \\
\alpha^{o}=0.25\end{array}$ & $\begin{array}{c}\alpha^{l o}=1 \\
\alpha^{o}=0.25\end{array}$ \\
\hline GDP loss [\%] & $5.88(0.41)$ & $4.98(0.42)$ & $5.47(0.71)$ & $4.64(0.46)$ & $4.1(1.14)$ \\
Mortality [\%] & $0.0167(0.0047)$ & $0.0612(0.0086)$ & $0.0169(0.0045)$ & $0.0526(0.0116)$ & $0.0115(0.0048)$ \\
Dur. Lock-down [add'l days] & $111.3(89.81)$ & $70.0(82.64)$ & $83.65(85.57)$ & $31.15(50.6)$ & $55.3(62.93)$ \\
Switch Opening/Lock-down & $6.85(1.5)$ & $4.95(0.94)$ & $5.1(1.52)$ & $2.75(0.85)$ & $3.15(2.16)$ \\
Pub. Acc. Deficit [\%] & $4.4(0.4)$ & $3.38(0.31)$ & $3.98(0.59)$ & $3.12(0.29)$ & $3.66(0.89)$ \\
\hline
\end{tabular}

50 there is no significant difference in GDP loss (see Appendix B) because a reintroduction of the lock-down policy is unlikely in these cases and they therefore result in similar GDP dynamics. For $\alpha^{l o}=1$ the economy suffers from a significantly higher GDP loss, which can be fully explained by the additional time the economy stays in lock-down. Apart from this time differences, the economy recovers in all scenarios. A thresholds of $\alpha^{l o}=1$ also leads to higher public account deficit, since the economy takes longer to recover. Given no significant difference in casualties between the different policy scenarios, a low value of $\alpha^{l o}$ linked to a higher GDP loss is inefficient. An optimal policy would therefore be to choose a threshold sufficiently high to ensure that the economy does never go back to the lock-down stage $\left(\alpha^{l o}>10\right)$. Given, that all stores have already been reopened in week 8 and the economy never goes back into lock-down, a variation of $\alpha^{o}$ is obsolete.

Exit with increase in the infection probability in the opening-up stage In the following, we again consider the case in which the relaxation of lock-down measures induces a reduction in the effect of individual prevention measures and assume that $\xi$ is reduced to $\xi^{o}=0.5$ in the opening phase, whereas it has the default value $\xi^{l}=0.6$ during lockdown. Since, this makes a second lock-down more likely, we now also consider variations 
in $\alpha^{o}$, that are however only effective after a second lock-down. Figure 10 shows the effects of different policies on mortality and GDP loss. The black line indicates the effect of a variation of the threshold $\alpha^{l o}$. A movement towards the top of the plot corresponds to an increase in $\alpha^{l o}$, towards the bottom a decrease in $\alpha^{l o}$. The blue lines correspond to changes in $\alpha^{o}$, where the point on the black line always represents $\alpha^{o}=0.0$, and moving along the line corresponds to higher values of $\alpha^{o}$. The default policy $\left(\alpha^{l o}=5, \alpha^{o}=0.0\right)$ is labeled with $A$. The optimal policy from the case without change in $\xi\left(\alpha^{l o}=50\right.$, $\left.\alpha^{o}=0.0\right)$ is labeled with 'B'. From Figure 10 we can already extract some key differences in comparison to the case without increase in the infection probability. Lower values of $\alpha^{\text {lo }}$ are no longer dominated by higher values. Moving from point 'A' to 'B', which corresponds to an increase of $\alpha^{l o}$ from 10 to 50, still decreases the economic loss, but also significantly increases the total number of casualties. Second, a full reopening after a second lockdown is not efficient. Starting from points 'A' or 'B', both indicators can be improved by increasing $\alpha^{o}$ to 0.25 or 0.5 (points ' $\mathrm{C}^{\prime}$ ' and ' $\mathrm{D}$ '). Even higher values of $\alpha^{o}$, however, do not reduce casualties in a significant way, but lead to considerably higher GDP losses. Third, both indicators can be improved by moving down the black line, decreasing $\alpha^{l o}$. A very low threshold, resulting in an early second lock-down, leads to a significantly reduced GDP loss. The optimal policy is at point $\mathrm{E}$, which combines a very low value for the threshold parameter $\left(\alpha^{l o}=1\right)$ with a moderately careful second opening $\left(\alpha^{o}=0.25\right)$.

The result that a lower threshold parameter and a smaller degree of opening reduces GDP loss, seems counter-intuitive at first and requires further explanation. Figure 11 shows the infection and GDP dynamics behind points A to E in Figure 10. Policies A to $\mathrm{D}$ have in common that the number of infected individuals stays comparatively high on average. At the same time, these policies lead to a much higher variance across runs. By analyzing the data of individual runs (not depicted here), we can verify that policies A to D almost always lead to one or more additional infection waves, followed by subsequent returns to the lock-down policy. Since the starting days and peaks of new waves are not synchronized across runs, this results in more or less flattish average curves for the infection dynamics. A more careful opening (policies C and D) is associated with a smaller slope of the infection curve, thereby increasing the time until another lock-down will be triggered. Table 14 shows that the additional duration in lock-down can be reduced significantly by reducing the degree of opening. Moving from point $\mathrm{B}$ to $\mathrm{D}$, by setting $\alpha^{o}=0.25$, the average days in lock-down reduces from 70.0 days to 31.15 days. The number of switches back to the lock-down policy is reduced from 4.95 to 2.75 . Table 14 also reveals that spending more time in lock-down does not necessarily increase GDP loss. At point E, the average additional time in lock-down is 55.3 days, significantly higher than in D. The GDP loss, however, is significantly smaller. Panel (b) in Figure 11 shows that the economy starts to recover later for $\alpha^{l o}=1$, but overtakes the other scenarios in the course of simulation. To explain this result, one has to again look at the individual run data: with the low threshold of $\alpha^{l o}=1$, a second lock-down is initiated early and lasts for a substantially longer period, compared to all other policies in question. As a consequence of the very low threshold, the lock-down policy is typically triggered again shortly after exit from the first lock-down. In return, it becomes very unlikely that the lock-down will be reactivated later in the simulation. This gives the economy a higher chance of uninterrupted recovery after an early second lock-down. In contrast, all other policies delay a second lock-down, but bear the risk of subsequent and late lock-downs, which would overall have more severe negative economic effects than an early second lock-down period.

Our findings for this section can be summarized as follows: For countries that already went through an extensive lock-down period, it makes no economic sense to risk a second 


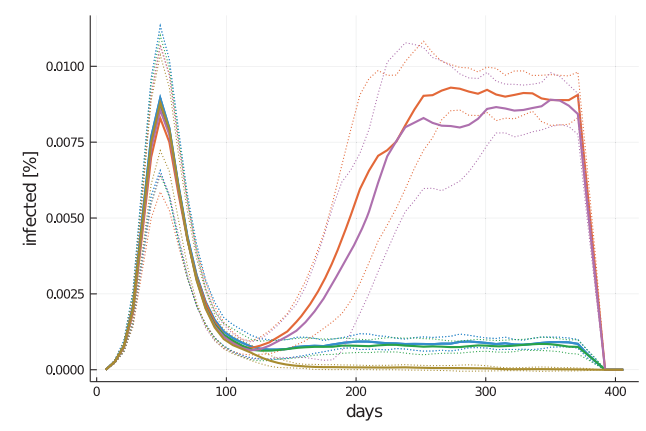

(a)

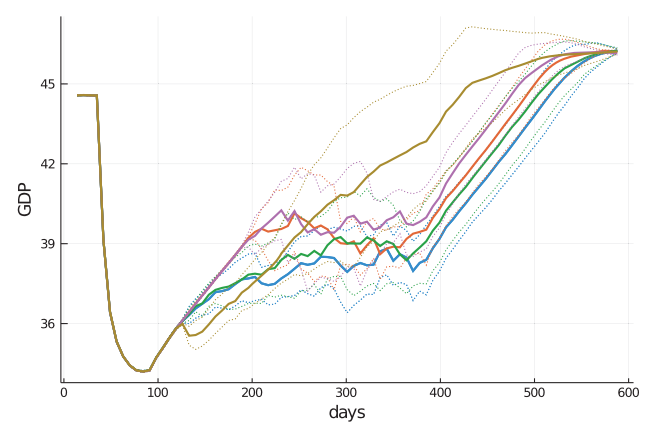

(b)

Figure 11: Dynamics of currently infected individuals (a) and GDP (b) for Points 'A' (blue), 'B' (red), 'C' (green), 'D' (purple), 'E' (orange).

wave. In case the opening has no negative side effects on the efficiency of individual prevention measures, a second wave is very unlikely to happen and a second lock-down is unnecessary. If, however, the individual infections probability increases as a result of opening up the economy, a second wave can only be avoided by a very strict threshold parameter. Higher threshold parameters would only delay an adequate response to an upcoming second wave and lead to economic costs of a late lock-down, that exceed the costs of an early second lock-down.

\section{Conclusions}

In this paper we develop a simulation model capable of jointly describing epidemiological and economic effects of measures aimed at containing the COVID-19 pandemic. The model has been calibrated using German data on the spread of COVID-19 and is wellsuited to replicate the course of the pandemic and economic effects of chosen policies in Germany. We consider several real-world policy measures that have been employed in the fight against COVID-19. This includes measures without direct economic impact, i.e. social distancing, home-office and individual prevention measures as well as measures that imply a reduction of economic activity, i.e. the closure of shops and services. In addition, we consider short-time working schemes and firm bailout programs aimed at mitigating the economic impact of COVID-19 and the associated containment measures.

We employ our model to, first, analyze the effect of different policy measures in a generic setting and, second, to explore optimal strategies for Germany after a long initial lockdown period of 11 weeks in total. Our analysis is based on the following two-stage policy: Two weeks after the appearance of the first infected individual, a lock-down policy is implemented, which is relaxed as soon as the number of newly infected individuals falls below a certain threshold (open-up-stage) and is re-implemented in case this number exceeds this threshold again. In both, the lock-down- and open-up-stage, the policy maker has to set the degree of closure/opening and hence has three parameters of freedom including the threshold. We start from a default policy and then systematically examine the implications of varying the three parameters. We find that having a threshold above 5 newly infected per 100.000 individuals is generally not efficient. At a threshold of 5, varying the degree of closure during lock-down shows that there is a trade-off between economic cost and mortality of the virus. For the opening-up stage it is efficient to fully or at least almost 
fully lifting restrictions on economic activities. These results, however, crucially depend on unaltered efficiency of individual prevention measures. In case that opening-up leads to an increase in individual infection probability, the costs of having a higher lock-down threshold strongly increase and a more cautious opening is efficient. Regardless of the chosen containment measures, the introduction of economic support measures, avoiding mass unemployment and bankruptcies, reduces the economic loss of the containment measures by a factor of approximately two without generating a higher deficit in the public account.

As a second part of our analysis, we apply our model to the German case in order to find optimal exit strategies from a longer lock-down period. As a response to the pandemic, the German government introduced a lock-down period of approximately 7 weeks for stores and 11 weeks for social contacts, followed by an adaptive policy with a threshold of 50 newly infected per 100.000 individuals. Measures to contain the pandemic have been accompanied by measures to mitigate the negative economic impact, i.e. a short-time working scheme and a bailout program for firms in distress. We also incorporate these measures in our model. Our analysis shows that, after the longer lock-down period, a second wave of infections is unlikely and a high threshold of 50 is reasonable. This again crucially depends on the unabated efficiency of individual prevention measures. If the individual infection probability increases as a result of the opening, we propose to set a very low threshold in order to immediately react to an increase in the number of newly infected individuals, since a delayed reaction would lead to higher economic costs later on.

The existing literature on the spread and economic consequences of COVID-19, so far, is mainly based on simple, analytical economic models that cannot be easily applied to real-world policy scenarios. Our main contribution is the integration of a standard SIRDtype epidemiological model into a rather rich agent-based macroeconomic framework. This approach allows us to jointly study the epidemiological and economic effects of different containment measures and to shed light on the interplay between economic activity and propagation of the virus. In addition, we are able to analyze the effects of detailed realworld economic policies, such as short time working schemes and bailout programs. Using data from Germany, we show, that the approach is capable of replicating both epidemiological and economic facts and serves as a useful tool for policy analysis. The model can be calibrated to data from other countries and easily extended to analyze the effects of other policies like policies specifically tailored at protecting the elderly. Another promising extension is the integration of heterogeneity of infection probabilities across individuals to account also for super-spreaders, i.e. individuals that have a much higher tendency to infect others and are suspected to play an important role in the propagation of COVID19. Also, epidemic and economic effects of (clustered) social networks determining contact schemes and the effect of different variants of (targeted) quarantine policies can be analyzed in the framework of the model developed here. 


\section{References}

Acemoglu, D., V. Chernozhukov, I. Werning, and M. D. Whinston (2020). A Mulit-Risk SIR Model With Optimally Targeted Lockdown. NBER Working Paper.

Adam, D. (2020). Special report: The simulations driving the world's response to COVID19. Nature 580(7803), 316-318.

Alvarez, F. E., D. Argente, and F. Lippi (2020). A simple planning problem for covid-19 lockdown.

Anesi, G. L. (2020). Coronavirus disease 2019 (COVID-19): Critical care issues.

Bommer, C. and S. Vollmer (2020). Average detection rate of SARS-CoV-2 infections. (February 2019), 1-13.

Bundesagentur für Arbeit (2020). Monatsbericht zum Arbeits- und Ausbildungsstand. Berichte: Blickpunkt Arbeitsmarkt / April 2020 (April), 1-46.

Carroll, C. and L. Summers (1991). Consumption growth parallels income growth: Some new evidence. In B. Bernheim and J. Shoven (Eds.), National Saving and Economic Performance, pp. 305-348. Chicago: University of Chicago Press.

Chang, S. L., N. Harding, C. Zachreson, O. M. Cliff, and M. Prokopenko (2020). Modelling transmission and control of the COVID-19 pandemic in Australia. arXiv, 1-31.

Coibion, O., Y. Gorodnichenko, and M. Weber (2020). The cost of the covid-19 crisis: Lockdowns, macroeconomic expectations, and consumer spending.

Dawid, H., P. Harting, and M. Neugart (2014). Economic convergence: Policy implications from a heterogeneous agent model. Journal of Economic Dynamics and Control 44, 5480 .

Dawid, H., P. Harting, and M. Neugart (2018). Cohesion policy and inequality dynamics: Insights from a heterogeneous agents macroeconomic model. Journal of Economic Behavior and Organization 150, 220-255.

Dawid, H., P. Harting, S. Van der Hoog, and M. Neugart (2019). Macroeconomics with Heterogeneous Agent Models: Fostering Transparency, Reproducibility and Replication. Journal of Evolutionary Economics 29, 467-538.

Deaton, A. (1991). Saving and liquidity constraints. Econometrica 59, 1221-1248.

Dorn, F., C. Fuest, M. Göttert, C. Krolage, S. Lautenbacher, S. Link, A. Peichl, M. Reif, S. Sauer, M. Stöckli, et al. (2020). Die volkswirtschaftlichen kosten des corona-shutdown für deutschland: Eine szenarienrechnung. ifo Schnelldienst 73(04), 29-35.

Eichenbaum, M., S. Rebelo, and M. Trabandt (2020). The Marcoeconomics of Epidemics. Nber 53(9), 1689-1699.

Epstein, J. M. (2009). Modelling to contain pandemics. Nature 460 (August), 2009.

Fadinger, H. and J. Schymik (2020). The Costs and Benefits of Home Office during the Covid-19 Pandemic: Evidence from Infections and an Input-Output Model for Germany. 224. 
Ferguson, N. M., D. Laydon, G. Nedjati-Gilani, N. Imai, K. Ainslie, M. Baguelin, S. Bhatia, A. Boonyasiri, Z. Cucunubá, G. Cuomo-Dannenburg, A. Dighe, I. Dorigatti, H. Fu, K. Gaythorpe, W. Green, A. Hamlet, W. Hinsley, L. C. Okell, S. Van Elsland, H. Thompson, R. Verity, E. Volz, H. Wang, Y. Wang, P. Gt Walker, C. Walters, P. Winskill, C. Whittaker, C. A. Donnelly, S. Riley, and A. C. Ghani (2020). Impact of nonpharmaceutical interventions (NPIs) to reduce COVID-19 mortality and healthcare demand. (March), 3-20.

Foley, D. and J. D. Farmer (2009). The economy needs agent-based modelling. Nature 460(6), 685-686.

Ghorbani, A., F. Lorig, B. de Bruin, P. Davidsson, F. Dignum, V. Dignum, M. van der Hurk, M. Jensen, C. Kammler, K. Kreulen, L. G. Ludescher, A. Melchior, R. Mellema, C. Păstrăv, L. Vanhée, and H. Verhagen (2020). The ASSOCC Simulation Model: A Response to the Community Call for the COVID-19 Pandemic. Review of Artificial Societies and Social Simulation.

Hammond, R., J. Ornstein, M. Kasman, and R. Purcell (2020). Testing responses through agent-based computational epidemiology (TRACE).

Jones, C. J., T. Philippon, and V. Venkateswaran (2020). Optimal mitigation policies in a pandemic: Social distancing and working from home.

Kissler, S. M., C. Tedijanto, E. Goldstein, Y. H. Grad, and M. Lipsitch (2020). Projecting the transmission dynamics of SARS-CoV-2 through the postpandemic period. Science 2, eabb5793.

Krueger, D., H. Uhlig, and T. Xie (2020). Macroeconomic Dynamics and Reallocation in an Epidemic.

Lehrer, R., S. Juhl, A. G. Blom, A. Wenz, T. Rettig, M. Reifenscheid, E. Naumann, K. Möhring, U. Krieger, S. Friedel, M. Fikel, and C. Cornesse (2020). Die Mannheimer Corona-Studie : Die vier Phasen des Social Distancing in Deutschland. (April), 1-34.

Miclo, L., D. Spiro, and J. Weibull (2020). Optimal epidemic suppression under an icu constraint. arXiv preprint arXiv:2005.01327.

Möhring, K., E. Naumann, M. Reifenscheid, A. G. Blom, A. Wenz, T. Rettig, R. Lehrer, U. Krieger, S. Juhl, S. Friedel, M. Fikel, and C. Cornesse (2020). Die Mannheimer Corona-Studie : Schwerpunktbericht zur Erwerbstätigkeit in Deutschland. (April).

Mossong, J., N. Hens, M. Jit, P. Beutels, K. Auranen, R. Mikolajczyk, M. Massari, S. Salmaso, G. S. Tomba, J. Wallinga, J. Heijne, M. Sadkowska-Todys, M. Rosinska, and W. J. Edmunds (2008). Social contacts and mixing patterns relevant to the spread of infectious diseases. PLoS Medicine 5(3), 0381-0391.

Pichler, A., M. Pangallo, R. M. del Rio-Chanona, F. Lafond, and J. D. Farmer (2020). Production networks and epidemic spreading: How to restart the UK economy? INET Working Paper.

Read, J. M., J. R. Bridgen, D. A. Cummings, A. Ho, and C. P. Jewell (2020). Novel coronavirus 2019-nCoV: early estimation of epidemiological parameters and epidemic predictions. MedRxiv (January). 
Rhodes, A., P. Ferdinande, H. Flaatten, B. Guidet, P. G. Metnitz, and R. P. Moreno (2012). The variability of critical care bed numbers in Europe. Intensive Care Medicine 38(10), 1647-1653.

Robert Koch Institut (2020). Coronavirus Disease 2019 Daily Situation Report of the Robert Koch Institute Epidemiological Situation in Germany, 20.04.2020.

Statistisches Bundesamt (2020). Volkswirtschaftliche Gesamtrechnungen.

Tuomisto, J. T., J. Yrjölä, M. Kolehmainen, J. Bonsdorff, J. Pekkanen, and T. Tikkanen (2020). An agent-based epidemic model REINA for COVID-19 to identify destructive policies. medRxiv, 1-29.

Verity, R., L. C. Okell, I. Dorigatti, P. Winskill, C. Whittaker, N. Imai, G. CuomoDannenburg, H. Thompson, P. G. Walker, H. Fu, A. Dighe, J. T. Griffin, M. Baguelin, S. Bhatia, A. Boonyasiri, A. Cori, Z. Cucunubá, R. FitzJohn, K. Gaythorpe, W. Green, A. Hamlet, W. Hinsley, D. Laydon, G. Nedjati-Gilani, S. Riley, S. van Elsland, E. Volz, H. Wang, Y. Wang, X. Xi, C. A. Donnelly, A. C. Ghani, and N. M. Ferguson (2020). Estimates of the severity of coronavirus disease 2019: a model-based analysis. The Lancet. Infectious diseases 3099(20), 1-9.

World Health Organisation (2020). Report of the WHO-China Joint Mission on Coronavirus Disease 2019 (COVID-19). 


\section{Appendix}

\section{A Detailed Model Description}

In this appendix, we provide a more detailed description of the model introduced in Section 2. The model has been implemented in Julia, the code is open source and can be downloaded from https://github.com/ETACE/ace_covid19.

\section{A.1 Timing}

The basic unit of time in the model is one day. denoted by $t \in \mathbb{N}_{+}$. The economic activities of the agents, however, take place on a weekly basis, where firms' production planning, labor market activities and delivery to the malls all take place at the first day of the week. Households consumption is spread out during the week since each household for each sector has a (randomly determined) shopping day during the week. In what follows, we denote by $w \in \mathbb{N}_{+}$the weeks during the simulation runs and when indexing a variable with the subscript ' $w$ ' we always refer to the first day of week $w$.

\section{A.2 The Economy}

\section{A.2.1 Firms}

A firm $i \in \mathbf{F}_{w}$ acts as a producer on the goods market and as employer on the labor market. It is assigned to one of the private sectors $k \in\{M, S, F\}$ and delivers only the mall that sells the products of sector $k$. Thus, all firms belonging to the same sector $k$ compete on the product market and form a set of direct competitors $\mathbf{F}_{k, w}$ of size $n_{k, w}$ in week $w$.

Production Planning A firm $i$ is characterized by a firm-specific level of labor productivity $A_{i}$ that is constant over time. The output of a firm is produced with labor as only input. Denote by $L_{i, w}$ the number of workers employed by firm $i$ in week $w$, the output of that firm is given by

$$
Q_{i, w}=A_{i} L_{i, w} .
$$

Production takes place on a weekly base. The production day is for all firms the same and fixed at the first day of the week. The output is delivered to the mall where each firm keeps an inventory stock. While the inventory is replenished once per week at the day of production, the products in the mall inventory can be sold on a daily base.

The output planning of a firm is based on a simple inventory rule with adaptive demand expectations, where $\hat{D}_{i, w}$ is the expected demand, which is updated according to

$$
\hat{D}_{i, w}=\left(1-\rho^{D}\right) \hat{D}_{i, w-1}+\rho^{D} D_{i, w-1},
$$

where $\rho^{D} \in(0,1)$ is a persistence parameter of the expectations and $D_{i, w-1}$ is the sum of the daily sales in the previous production and sales cycle. Denote by $Y_{i, w}$ the inventory stock of firm $i$ in the mall at the end of week $w$. Then the planned output quantity for the current production cycle is determined by

$$
\tilde{Q}_{i, w}= \begin{cases}\left(1+\chi_{k}\right) \hat{D}_{i, w}-\left(1-\delta_{k}\right) Y_{i, w-1}, & \text { if } Y_{i, w}>0 \\ \left(1+\iota \cdot \chi_{k}\right) \hat{D}_{i, w} & \text { if } Y_{i, w}=0\end{cases}
$$

where $\chi_{k}>0$ captures the size of a sector-specific inventory buffer and $\iota>1$ captures that firms might increase their buffer when their stock was sold out in the previous period 
since this is seen as a a signal for an expansion in demand. Parameter $\delta_{k} \in[0,1]$ describes a sector-specific depreciation of the inventory at the end of the sales cycle.

For reasons of simplicity we abstract from production time and the produced quantity is delivered to the mall at the beginning of the week before consumption starts. The inventory stock then updated every day depending on the weekly inflow of the replenishment and the daily outflow of sales. At a generic iteration $t$, the inventory stock in the mall changes according to ${ }^{21}$

$$
Y_{i, t}= \begin{cases}\left(1-\delta_{k}\right)\left(Y_{i, t-1}-X_{i, t-1}\right)+Q_{i, t} & \text { if } t \bmod 7=1 \\ Y_{i, t-1}-X_{i, t-1} & \text { else. }\end{cases}
$$

Labor Input Given the planned production volume and firm's production technology, the labor demand of the firm reads

$$
\tilde{L}_{i, w}=\frac{\tilde{Q}_{i, w}}{A_{i}} .
$$

Depending on the size of the workforce $L_{i, w-1}$ employed for the previous production cycle, the labor demand $\tilde{L}_{i, w}$ implies to hire additional workers or to dismiss some redundant workers of the firm. In the former case, i.e. if $\tilde{L}_{i, w}>L_{i, w-1}$, the firm has $L_{i, w}^{V}=\tilde{L}_{i, w}-$ $L_{i, w-1}$ vacancies from which, depending on the outcome of the labor market, $L_{i, w}^{F} \leq L_{i, w}^{V}$ will be filled. In the latter case, the firm has $L_{i, w}^{R}=L_{i, w-1}-\tilde{L}_{i, w}$ redundancies and the firm chooses randomly $L_{i, w}^{R}$ workers from the set $\mathbf{W}_{i, w}^{F}$ of current employees to be fired. Altogether, the size of the workforce evolves according to

$$
L_{i, w}= \begin{cases}L_{i, w-1}+L_{i, w}^{F} & \text { if } \tilde{L}_{i, w}>L_{i, w-1} \\ L_{i, w-1}-L_{i, w}^{R} & \text { else. }\end{cases}
$$

The weekly wage that firms pay to their workers is assumed to be constant over time. It is sector-specific and proportional to the average productivity $\bar{A}_{k}$ of the sector $k$ in which firm $i$ is active, i.e. ${ }^{22}$

$$
w_{i}=w_{k}=\psi_{k} \bar{A}_{k} \text { with } \psi_{k}>0 .
$$

Pricing and Accounting The firm applies mark-up pricing with an endogenous markup $\mu_{i, w}>0$ on unit costs to determine the price of its product. The unit costs of a firm are determined by the variable labor costs and fixed $\operatorname{costs} c_{i}^{F}$. The unit costs are then

$$
c_{i}=\frac{w_{i}+\frac{c_{i}^{F}}{L_{i, w}}}{A_{i}\left(1-\chi_{k} \delta_{k}\right)},
$$

such that the price of the firm is

$$
P_{i, w}=\left(1+\mu_{i, w}\right) c_{i} .
$$

The mark-up is updated at the day of production and depends on the market share of the firm. Denote by $s_{i, w}$ the market share (in terms of sold quantity) of firm $i$ on its relevant market in week $w$, then the mark-up equals

$$
\mu_{i, w+1}=\underline{\mu}_{k}+s_{i, w} \cdot\left(\bar{\mu}_{k}-\underline{\mu}_{k}\right),
$$

\footnotetext{
${ }^{21}$ Here and below $t \bmod 7$ denotes $t$ modulo 7 , i.e. $t-7\lfloor t / 7\rfloor$, where $\lfloor x\rfloor$ denotes the largest integer smaller or equal than $x$.

${ }^{22} \psi_{k}=\frac{\left(1-\chi_{k} \delta_{k}\right)}{\left(1+\lambda_{k}\right)\left(1+\underline{\mu}_{k}\right)}$ is the sector specific wage factor.
} 
where $\bar{\mu}_{k}$ and $\underline{\mu}_{k}$ are parameters determining the upper and, respectively, lower bound for the mark-up in sector $k$.

Accounting takes place at the day of production and is related to the previous production cycle. The profits of firm $i$ accounted for in period $w$ reads

$$
\Pi_{i, w}=P_{i, w} D_{i, t}-L_{i, w} w_{i}-c_{i}^{F} .
$$

The liquidity of the firm evolves according to

$$
S_{i, w}=S_{i, w-1}+\Pi_{i, w-1}-\max \left[0, \tau_{w-1} \Pi_{i, w-1}\right]-d_{i, w}-c_{i}^{F}
$$

Here, $\tau_{w}$ is the tax rate for corporate taxes on (positive) profits and $d_{i, w}$ are dividends paid out to the firm's shareholders. For the dividends, we define a dividend rate $\zeta \in(0,1)$ and a threshold savings level being proportional to the average firm revenues over the last $T$ weeks, i.e.

$$
\tilde{S}_{i, w}=\beta_{k} \frac{1}{T} \sum_{\tau=0}^{T-1} \Pi_{i, w-\tau} D_{i, w-\tau} .
$$

Firms pay out their entire (after tax) profits as dividend once their savings are above that threshold, otherwise they put a fraction of the profits into their savings:

$$
d_{i, w}= \begin{cases}\left(1-\tau_{w}\right) \max \left[0, \Pi_{i, w}\right] & \text { if } S_{i, w-1}+\left(1-\tau_{w}\right) \max \left[0, \Pi_{i, w}\right]>\tilde{S}_{i, w} \\ \zeta\left(1-\tau_{w}\right) \max \left[0, \Pi_{i, w}\right] & \text { else }\end{cases}
$$

with $\zeta<1$. The dividends as well as fixed costs are distributed equally to all households.

If a firm has a negative payment account at the end of the accounting, it has to declare bankruptcy. In this case, the firm becomes inactive and has to dismiss all workers. At the same time, the inventory of its product stored in the mall is fully written off.

\section{A.2.2 Households}

There are $m_{t}$ households populating the economy. A household $h \in \mathbf{H}_{t}$ acts as costumer on the goods market and, depending on her age, as an employee on the labor market.

Age Structure and Labor Supply Households are classified into a young cohort $\mathbf{H}_{t}^{Y}$ and an old cohort $\mathbf{H}_{t}^{O}$. Members of the old cohort are retired, whereas households in the young cohort constitute the labor force of the economy. A young household can be employed or unemployed. If a household is unemployed, she enters the labor market to search for a new job.

Households have work-related skills that can only be utilized in one of the sectors $k \in$ $\{M, S, F\}$ and cannot be transferred to other sectors. Thus, households are uniquely assigned to one sector and determine the sector-specific labor supply $\mathbf{L}_{k, t}^{S}$. Apart from the private sectors, there is also a public sector (indexed by $k=P$ ) that does not produce any market goods. In this sector, the government operates $n_{P}$ offices and households that work for the government as civil servants have a permanent and secure job.

In each sector, we assume that there is a fixed proportion $h_{k}^{H O}$ of workers qualified to execute specific tasks that can potentially be done from home. The workers for whom it is possible to carry out home-based office work are summarized in set $\mathbf{L}_{k, t}^{H O} \subset \mathbf{L}_{k, t}^{S}$. 
Income and Saving Decision Depending on their age and employment status, households have different income sources. Employed households earn a labor income $\omega_{h, w}$ that equals the wage $w_{k}$ of the sector $k$ in which a household is employed. Unemployed households, instead, receive unemployment benefits $u_{h, w}$ from the government that correspond to a fraction $\nu$ of her last labor income. Old households live on pensions of level $w^{P}$ that are paid by the government and are uniform and constant over time for all retirees in the economy. Additionally, all households receive a capital income that correspond to an equal share of the fixed costs paid by firms and dividends distributed by the firms, i.e.

$$
I_{h, w}^{C a p}=\frac{1}{m_{w}} \sum_{\forall i \in \mathbf{F}_{w}}\left(d_{i, w}+c_{i}^{F}\right) .
$$

Altogether, the overall gross income $I_{h, w}$ of household $h$ in week $w$ equals

$$
I_{h, w}= \begin{cases}\omega_{h, w}+I_{h, w}^{C a p} & \text { if employed } \\ u_{h, w}+I_{h, w}^{C a p} & \text { if unemployed } \\ w^{P}+I_{h, w}^{C a p} & \text { if retired. }\end{cases}
$$

All sources of income are subject to income tax. Given tax rate $\tau_{w}$, the net income of household $h$ is then

$$
I_{h, w}^{N}=\left(1-\tau_{w}\right) I_{h, w} .
$$

On the first day of the week, the household decides on the budget $C_{h, w}$ that she plans to spend in the coming week. For the consumption and saving decision, the household takes into account an average net income

$$
\bar{I}_{h, w}^{N}=\left(1-\rho^{I}\right) \bar{I}_{h, w-1}+\rho^{I} I_{h, w}^{N}
$$

as well as her total wealth $W_{h, w}$, which consists of her money holdings. The notional consumption budget is determined according to the consumption rule

$$
C_{h, w}=\bar{I}_{h, w}^{N}+\kappa \cdot\left(W_{h, w}-\Phi \cdot \bar{I}_{h, w}^{N}\right),
$$

where the parameter $\Phi$ is the target wealth/income ratio. This formulation is motivated by the "buffer stock" theory of consumption which is backed up by theoretical arguments and substantial empirical evidence (see Deaton, 1991, Carroll and Summers, 1991). The parameter $\Phi$ describes how large the targeted buffer is relative to income, and $\kappa$ indicates how sensitively consumption reacts to deviations of the actual wealth-to-income ratio to the target level.

Finally, the consumption budget $C_{h, w}$ is allocated to the different sectors. In principle, the budget that a household $h$ tries to spend for products from sector $k \in\{M, S, F\}$ is determined by a fixed allocation across sectors, i.e.

$$
\tilde{C}_{h, k, w}^{S}=c_{k} C_{h, w} .
$$

However, sector $k=F$ is different from the other sectors in a way that it includes essential goods implying that households try to avoid large spending cuts for these products. Hence, the actual consumption budget allocated to the essential sector $F$ is

$$
C_{h, F, w}^{S}=\max \left[c_{F} C_{h, w}, \min \left[(1-\phi) C_{h, F, w-1}^{S}, C_{h, w}\right]\right] .
$$


The remaining budget, instead, is distributed proportionally among the non-essential sectors $k \neq F$ according to the consumption quotas $c_{k}$ such that

$$
C_{h, k, w}^{S}=\frac{c_{k}}{\sum_{l \in \mathbf{K} \backslash\left\{k^{*}\right\}} c_{l}}\left(C_{h, w}-C_{h, F, w}^{S}\right) .
$$

A households has different shopping days for the products, where the actual expenditures can deviate from planned ones due to rationing (see below). Denote by $E_{h, t} \geq 0$ the total expenditures for consumption on a generic day $t$, then the savings of household $h$ evolve according to

$$
W_{h, t}= \begin{cases}W_{h, t-1}-E_{h, t-1}+I_{h, t}^{N} & \text { if } t \bmod 7=1 \\ W_{h, t-1}-E_{h, t-1} & \text { else. }\end{cases}
$$

\section{A.2.3 Labor Market Interactions}

The labor market is modeled as a decentralized market with separated sub markets for each sector. The labor market operates every first day of the week to match open vacancies and job seekers. All firms belonging to sector $k$ that have open vacancies $L_{i, w}^{V}>0$ try to get matched with the unemployed workers $\mathbf{U}_{k, w}^{S}$ searching for a job in sector $k$. All households $h \in \mathbf{W}_{P, w}^{S}$ that work in the public sector stay with their employee throughout the simulation run and are never active on the labor market.

The matching process is modeled in a way that firms open vacancies in a random sequence and unemployed job seekers with appropriate skills apply. The firm then hires on a first-come-first-serve basis. If at the time of the announcement of the job opening there are no unemployed job seekers with appropriate skills, the firm is rationed and can only hire again in the following week.

More precisely, suppose $\mathbf{V}_{k, w}$ is the randomly ordered set of firms in the queue of sector $k$ in week $w$ and $v_{l} \in \mathbf{V}_{k, w}$ is the firm ranked at the $l$-th position. Denote by $\tilde{L}_{k, w, l}^{S}$ the number of unemployed in sector $k$ after firm $v_{l}$ has been active on the labor market with $\tilde{L}_{k, w, 0}^{S}=\left|\mathbf{U}_{k, w}^{S}\right|$. Then for all firms $v_{l} \in \mathbf{V}_{k, w}$ we have that the number of hired respectively fired workers in week $w$ is given by

$$
\begin{array}{ll}
L_{i, w}^{F}=\min \left[\tilde{L}_{i, w}-L_{i, w-1}, \tilde{L}_{k, w, l-1}^{S}\right] & \text { if } \tilde{L}_{i, w} \geq L_{i, w-1} \\
L_{i, w}^{R}=\tilde{L}_{i, w-1}-L_{i, w} & \text { else. }
\end{array}
$$

The number of unemployed evolves according to

$$
\tilde{L}_{k, w, l}^{S}=\tilde{L}_{k, w, l-1}^{S}-L_{i, w}^{F}+L_{i, w}^{R} .
$$

Hence, a firm might be rationed on the labor market if the number of job-seekers when the firm is active on the market is below its labor demand. It might happen that firms that become active after a rationed firm can nevertheless hire because some firm in the queue in-between has fired workers.

\section{A.2.4 Goods Market Interactions}

Once per week, a household determines randomly a shopping day for each sector within the next 7 days. At the respective shopping day for sector $k$, the household $h$ visits a mall in which those products are sold. Denote by $\mathbf{C}_{k, t}$ the ordered set of costumers shopping in sector $k$ at day $t$ and by $c_{l} \in \mathbf{C}_{k, t}$ the consumer at the $l$-th position in the queue. Furthermore, denote by $\tilde{Y}_{i, t, l}$ the inventory of firm $i$ in the mall after consumer $c_{l}$ has 
completed her shopping and by $\mathbf{A}_{t, l}$ the set of active firms at that point, i.e. those firms $i$ for which $\tilde{Y}_{i, t, l}>0$ holds.

Consumer $c_{l}$ draws a random subset $\boldsymbol{\Omega}_{c_{l}, k, t} \subseteq \mathbf{A}_{t, l}$ of size $\eta$ of the products offered by active firms in the mall. The decision which product $i \in \boldsymbol{\Omega}_{c_{l}, k, t}$ of sector $k$ to purchase is based on a logit choice model. The probability to buy the product from firm $i$ that is offered at price $P_{i, w_{t}}$, where $w_{t}$ is the week of day $t$, is

$$
\mathbb{P}\left[c_{l} \text { selects } i \in \boldsymbol{\Omega}_{c_{l}, k, t}\right]=\frac{\exp \left(-\gamma^{C} \log \left(P_{i, w_{t}}\right)\right)}{\sum_{\forall j \in \Omega_{c_{l}, k, t}} \exp \left(-\gamma^{C} \log \left(P_{j, w_{t}}\right)\right)},
$$

where $\gamma^{C}$ is a parameter for the price sensitivity of households. The notional quantity to purchase is then

$$
\mathcal{C}_{c_{l}, i, t}=\min \left[\frac{C_{c_{l}, k, w_{t}}^{S}}{P_{i, w_{t}}}, \tilde{Y}_{i, t, l-1}\right] .
$$

The stock of the product of firm $i$ still available at the mall is updated according to

$$
\tilde{Y}_{i, t, l}=\tilde{Y}_{i, t, l-1}-\mathcal{C}_{c_{l}, i, t} .
$$

If $\tilde{Y}_{i, t, l}=0$, then the firm becomes inactive in the mall at this point and only becomes active again at the first day of the following week when new quantities of the product are delivered to the mall. If there are no active firms in the mall when a household $h$ visits the mall or if the chosen firm is not able to supply to total amount demanded, i.e. $\tilde{Y}_{i, t, l-1}<\frac{C_{c_{l}, k, w_{t}}^{S}}{P_{i, w_{t}}}$, then the consumer is rationed and returns to the mall again the following day. All parts of the foreseen weekly consumption budget for sector $k$ which have not been spent at that point are added to the household's savings.

\section{A.2.5 Government and Public Sector}

The government collects income and profit taxes to fund the civil servants working in one of the $n_{P}$ offices in $\mathbf{G}$ comprising the public sector, the payment of unemployment benefits and pensions to old households. Additionally, the government can pay subsidies or other financial support to households and firms as part of additional policies.

Each office $g \in \mathbf{G}$ of the public sector employs a set of civil servants $\mathbf{W}_{g}^{G} \subset \mathbf{H}_{0}^{Y}$ that does change over time only if an employee dies. The total number of civil servants in the economy in week $w$ is denoted by $L_{w}^{P}$.

Unemployment benefits are based on the last wage of an unemployed worker with replacement rate $\nu$. Pensions are uniform for all old households and are a percentage pen of the average wage in the economy. Households employed in the public sector earn a wage $w^{P}$.

Tax collection and distribution of unemployment benefits and pensions takes place at the first day of the week. The tax revenue of the government is the sum of the corporate tax revenues

$$
T_{w}^{C}=\sum_{i \in \mathbf{F}_{\mathbf{w}}} \max \left[0, \tau_{w} \Pi_{i, w}\right]
$$

and the income tax revenues are

$$
T_{w}^{I}=\tau_{w} \sum_{h \in \mathbf{W}_{w}} \omega_{h, w}+\tau_{w} \sum_{h \in \mathbf{H}_{w}} I_{h, w}^{C a p}+\tau_{w} \sum_{h \in \mathbf{U}_{w}} u_{h, w}+\tau_{w} w^{P}\left|\mathbf{H}_{w}^{O}\right|,
$$


where $\mathbf{W}_{w}$ denotes the set of all employed households in the economy in week $w$. Denoting by $\mathbf{U}_{w}$ the set of unemployed workers in the economy, the public account of the government evolves according to

$$
S_{w}^{G}=S_{w-1}^{G}+T^{C}+T^{I}-\sum_{h \in \mathbf{U}_{w}} u_{h, w}-w^{P}\left|\mathbf{H}_{w}^{O}\right|-w_{0}^{S} L^{P}
$$

The government adjusts the tax rate over time in order to keep a target level of the public account. In the baseline setup, the tax rate $\tau_{w}$ evolves according to

$$
\tau_{w}=\left(1-\rho^{T}\right) \tau_{w-1}+\rho^{T} \hat{\tau}_{w},
$$

where $\hat{\tau}_{w}$ is the tax rate that would be sufficient to balance the budget on a target public account level. In particular,

$$
\hat{\tau}_{w}=\max \left[0, \frac{\sum_{h \in \mathbf{U}_{w}} u_{h, w}+w^{P}\left|\mathbf{H}_{w}^{O}\right|+w_{0}^{S} L^{P}-\theta S_{w}^{G}}{\frac{T^{C}}{\tau}+\sum_{h \in \mathbf{W}_{w}} \omega_{h, w}}\right],
$$

Note that the target level of public account and the speed of tax rate adjustment might change as part of policy.

Finally, the government compute the gross domestic product for the last week according to

$$
G D P_{w}=w_{0}^{S} L^{P}+\sum_{k \in \mathbf{K}} \sum_{i \in \mathbf{F}_{k, w}} P_{i, w} Q_{i, w}
$$

\section{A.2.6 Social Interactions}

Social interactions take place in three different occasions. The first type of social interactions occurs at work. Firms and public offices represent the work environment where social contacts in the professional context occur. Suppose $\mathbf{X}_{h, t}=\mathbf{W}_{i, t}^{F} \backslash\{h\}$ is the set of household $h$ 's colleagues at time $t$ (or $\mathbf{X}_{h, t}=\mathbf{W}_{g}^{G} \backslash\{h\}$ for public servants). As long as she is not in the short-term program or working from home, the worker faces several potential meetings with her co-workers, where

$$
\tilde{\mathbf{X}}_{h, t}= \begin{cases}\emptyset & h \in\left(\mathbf{W}_{i, t}^{H O} \cup \mathbf{W}_{i, t}^{S T}\right) \\ \mathbf{X}_{h, t} \backslash\left(\mathbf{W}_{i, t}^{H O} \cup \mathbf{W}_{i, t}^{S T}\right) & \text { else }\end{cases}
$$

is the set of co-workers worker $h$ can potentially meet during a workday. As defined above, $\mathbf{W}_{i, t}^{H O}$ is the set of workers in home-office and $\mathbf{W}_{i, t}^{S T}$ is the set of workers on short-time work on day $t$. The realized number of meetings is drawn from a distribution where the maximum contact threshold $n_{k}^{w}$ might differ across sectors. The number (cardinality) of colleagues $N_{h, t}^{c w} \in\left[0, n_{k}^{w}\right]$ met by agent $h$ is a uniform random draw with probability $p_{k}^{c w}=\frac{1}{n_{k}^{w}+1}$. The set of actually met co-workers of agent $h$ at time $t$ is $\mathbf{C W}_{h, t} \subset\left(\tilde{\mathbf{X}}_{h, t} \cup \emptyset\right)$.

The second possibility to interact with other households takes place during shopping. Households visit different shopping malls within a week in order to purchase or consume goods offered by the three private sectors. The maximum number of possible meetings at one shopping day is drawn from a distribution where the upper threshold $n_{k}^{c}$ is sector specific. The actual number of people met in the specific mall is given by the fraction of the population going to that mall times the maximum number of possible meetings across the week. Thus, if one seventh of the local population is going to that mall, the number 
of contacts when shopping will be equal to the maximum number of possible contacts. Formally

$$
N_{h, k, t}^{c s}=\bar{N}_{h, k, t}^{c s} \cdot \frac{\left|\mathbf{C}_{k, t}\right|}{\left|\mathbf{H}_{t}\right|} \cdot 7,
$$

where $\left|\mathbf{C}_{k, t}\right|$ is the number of customers of sector $k$ at time $t$ and $\mathbf{C}_{k, t}=\sum_{i} \mathbf{C}_{i, t},\left|\mathbf{H}_{t}\right|$ is the number of households at time $t, \bar{N}_{h, k, t}^{c s} \in\left[0, n_{k}^{c}\right]$ is the upper bound cardinality of coshoppers met by agent $h$ in sector $k$ at time $t$ and it is drawn from a uniform distribution with probability $p_{k}^{c s}=\frac{1}{n_{k}^{c}+1}$. Thus, the actual set of individuals met while shopping at the local mall is drawn from a distribution, multiple meetings with the same household are possible. $\mathbf{C S}_{h, k, t} \subset \mathbf{C}_{k, t}$ is the set of met co-shoppers of agent $h$ in sector $k$ at period $t$.

Finally, households engage in other social activities, where those social interactions are characterized by heterogeneous cross age patterns. In particular, the number of contacts for each type of cross age meeting is drawn from a uniform distribution whose upper bound $n_{a, a}^{p}$ with $a \in\{y, o\}$ reflects the cross age interaction patterns. In case of a positive number of contacts for period $t$, potential partners are drawn among the population belonging to the specific age group. $\mathbf{H}_{-h, t}^{a}$ is the set of households belonging to a specific age group (young or old) surrounding agent $h$ at time $t$. We select the number (cardinality) of people $N_{h, t}^{a, a} \in\left[0, n_{a, a}^{p}\right]$ met by agent $h$ at time $t$ with probability $p_{a, a}^{s a}=\frac{1}{n_{a, a}^{p}+1}$. Then, the set of households belonging to a specific age group met by agent $h$ at time $t$ is $\mathbf{S A}_{h, t}^{a} \subset \mathbf{H}_{-h, t}^{a}$.

\section{A.2.7 Pandemic Dynamics}

Households differ with respect to their health states. At every instant of time $t$, each household $h$ may be in one of four states. "Susceptible", not yet been exposed to the virus and thus not immune, "Infected" already contracted the virus, "Recovered" been infected, survived the virus and acquired immunity and "Deceased" died from the virus. In particular, we further detail the infected state into three different phases which do matter in terms of virus transmission. Thus, we distinguish between a latency phase of length $t_{l n t}$, an infectious phase of length $t_{\text {inf }}$ and a post-infectious period where one has not yet recovered. $\bar{t}_{r e c}$ is the maximum number of days being infected or the recovery time. The set of households belonging to the four health states are denoted by $\mathbf{S}_{t}, \mathbf{I}_{t}$, $\mathbf{R}_{t}$ and $\mathbf{D}_{t}$, respectively. The set of infectious agents is denoted by $\mathbf{I}_{t}^{\text {inf }} \subseteq \mathbf{I}_{t}$ and that of newly infected people is denoted by $\mathbf{T}_{t}$. Thus the population of alive households evolves together with the epidemic and changes over time such that:

$$
\mathbf{H}_{t}=\mathbf{S}_{t}+\mathbf{I}_{t}+\mathbf{R}_{t}
$$

In other words, the population decreases due to death from the disease while we abstract from other demographic dynamics such as births and other causes of death. We assume that the initial stocks of infected, recovered and deceased individuals are set equal to zero. Hence, before the outbreak of the epidemic, the entire initial population of household belongs to the susceptible group.

At period $t=t_{0}$, the epidemic starts. The initial infected agents are randomly selected, their state is updated and their recovery countdown starts. The rest of the population stays susceptible but is exposed to three channels through which the infection can be transmitted, social contacts at work, during consumption and other social occasions, where only meetings with infectious households might result in the contagious.

In every contact between an infectious household $h \in \mathbf{I}_{t}^{\text {inf }}$ and a susceptible household $\tilde{h} \in \mathbf{S}_{t}$ the virus is transmitted with a probability $(1-\xi) p_{\text {inf }}$, where without any policy measure $\xi=0$. An infected agent $h$ at each possible day has a small probability $q_{t}^{a}$ to die 
from the virus. In this case, she is removed from the unemployment list if unemployed or from the list of workers of her employer if employed. Also the number of casualties is updated. After $\bar{t}_{r e c}$ days of infection the household is recovered and afterwards immune to the virus.

The case fatality rates $q_{t}^{a}$ with $a=\{y, o\}$ do not only depend on the age of the household, but also on the degree of utilization of intensive care units in the economy at $t$. In case of a over-utilization, the rate is increasing with $\left|\mathbf{I}_{t}\right|$. In particular, depending on the degree of over-utilization, the age-specific fatality rate is a weighted average between a regular fatality rate $\bar{q}_{l}^{a}$ achieved with under-utilized intensive care units and a fatality rate $\bar{q}_{h}^{a}$ that would be achieved if no intensive care capacities would be available. Formally

$$
q_{t}^{a}=\left[\frac{\min \left(n^{i c u}, u^{i c u} \cdot\left|\mathbf{I}_{t}\right|\right)}{u^{i c u} \cdot\left|\mathbf{I}_{t}\right|}\right] \bar{q}_{l}^{a}+\left[1-\frac{\min \left(n^{i c u}, u^{i c u} \cdot\left|\mathbf{I}_{t}\right|\right)}{u^{i c u} \cdot\left|\mathbf{I}_{t}\right|}\right] \bar{q}_{h}^{a}
$$

where $n^{i c u}, u^{i c u},\left|\mathbf{I}_{t}\right|$ are, respectively, the number of intensive care beds available, the fraction of infected individuals in need of intensive care and the total number of actual infected.

We assume that after $t_{v a c}$ days from the beginning of the pandemic, a vaccine is available on the market and all susceptible households are assumed to receive immediate vaccination. Thus, the probability of infection $p_{\text {inf }}$ goes to zero and the epidemic washes out as soon as infected households recover or die.

\section{A.3 How to compute the $R_{0}$ index}

A widely used statistic to recognize the strength of an epidemic is the basic reproduction number $R_{0}$. This statistic is the expected total number of infections directly generated by one infected person, in other words the average number of people to whom one infected person will pass the virus. The higher the value of $R_{0}$, the faster is the spread of the virus. Direct observations and estimations of $R_{0}$ are possible in our model. A direct observation can be achieved by taking the simple daily average of the number of secondary infections of each infected individual

$$
R_{0, t}=\frac{1}{\left|\mathbf{H}_{t}\right|} \sum_{h} I_{h, t}^{2}
$$

where $I_{h, t}^{2}$ is the cumulative number of secondary infections caused by household $h$ at time $t$.

With respect to estimation, we follow the methodology applied by the Robert Koch Institute. The generation time describes the average time span from the infection of a person to the infection of the subsequent cases infected by that same person. It corresponds approximately to the serial interval, which indicates the mean duration between the onset of illness in a case and the onset of illness in its subsequent cases. We estimate this period of time to be $t_{g e n}$ days because the infectivity at the beginning of the infection is particularly high and the infected person is not aware before the onset of symptoms that she can already infect others. ${ }^{23}$ With a constant generation time of $t_{\text {gen }}$ days, the reproduction number is the fraction between the number of new illnesses in two successive

\footnotetext{
${ }^{23}$ The generation time is not a stable property of the pathogen, but, like the reproduction number, depends on various factors and can change over time. For example, measures to isolate confirmed cases and quarantine contact persons not only reduce the number of follow-up cases, but also shorten the generation time because the few infections occur right at the beginning of the infection.
} 
time segments of $t_{g e n}$ days each.

$$
R_{0, t}^{R K I}=\frac{\left|\mathbf{I}_{t}+\mathbf{R}_{t}\right|-\left|\mathbf{I}_{t-t_{g e n}}+\mathbf{R}_{t-t_{g e n}}\right|}{\left|\mathbf{I}_{t-t_{g e n}}+\mathbf{R}_{t-t_{g e n}}\right|-\left|\mathbf{I}_{t-2 t_{g e n}}+\mathbf{R}_{t-2 t_{g e n}}\right|}
$$

The $R_{0}^{R K I}$ value determined in this way is assigned to the last of these $2 \cdot t_{g e n}$ days because only then all the information is available. Therefore, the $R_{0}^{R K I}$-value does not describe a single day, but rather an interval of $t_{\text {gen }}$ days. If the number of new cases increased in the second period, the $R_{0}^{R K I}$ is above 1 . If the number of new cases is the same in both periods, the basic reproduction number is 1 . This corresponds to a linear increase in the number of cases. If, on the other hand, only every second case infects another person, i.e. $R_{0}^{R K I}=0.5$, then the number of new infections halves within the generation period. The basic reproduction number alone is not sufficient to describe the current state of evolution of the pandemic. At least the absolute number of new illnesses and also the intensive care capacity utilization have to be considered in order to get an adequate picture. ${ }^{24}$

\footnotetext{
${ }^{24}$ Another aspect is also that the test capacities in Germany have been increased significantly and thus a larger part of the infected becomes visible. This structural effect and the resulting increase in the number of reports can lead to the current $R_{0}^{R K I}$-value somehow overestimating real events. Adjustment for the higher test rates is not possible because there is no sufficiently differentiated test data. Nevertheless, we weight all our calibration according to the German detection rate, see Bommer and Vollmer (2020)
} 


\section{B Statistical Tests}

This appendix provides the results from statistical tests we referred to in Section 4 and 5. To verify the statistical significance for differences between point A and points B, C, D and $\mathrm{E}$ in Figure 3, 5, 7 and 10 as well as between thresholds in Table 13 in mortality and average GDP loss, we use the Mann-Whitney-U test, a non-parametric test for unpaired samples. We document the $p$-values in Tables 15 - 19, which are based on 20 batch runs.

Table 15: $p$-values for Mann-Whitney-U tests between points from Figure 3.

\begin{tabular}{lcc}
\hline & \multicolumn{2}{c}{$\begin{array}{c}\text { Point A } \\
\text { average GDP loss }\end{array}$} \\
\hline Point B & $<0.0001$ & $<0.0001$ \\
Point C & 0.0904 & $<0.0001$ \\
Point D & $<0.0001$ & 0.1022 \\
Point E & 0.0682 & $<0.0001$ \\
\hline
\end{tabular}

Table 17: $p$-values for Mann-Whitney-U test between points from Figure 7.

\begin{tabular}{lcc}
\hline & \multicolumn{2}{c}{$\begin{array}{c}\text { Point A } \\
\text { average GDP loss }\end{array}$} \\
\hline Point B & $<0.0001$ & $<0.0001$ \\
Point C & 0.1426 & $<0.0001$ \\
Point D & $<0.0001$ & $<0.0001$ \\
Point E & 0.5142 & $<0.0001$ \\
\hline
\end{tabular}

Table 16: $p$-values for Mann-Whitney-U test between points from Figure 5 .

\begin{tabular}{lcc}
\hline & \multicolumn{2}{c}{$\begin{array}{c}\text { Point A } \\
\text { average GDP loss }\end{array}$} \\
\hline Point B & $<0.0001$ & $<0.0001$ \\
Point C & 0.1499 & 0.1207 \\
Point D & $<0.0001$ & 0.0013 \\
Point E & 0.8494 & $<0.0001$ \\
\hline
\end{tabular}

Table 18: $p$-values for Mann-Whitney-U test for thresholds from Table 13.

\begin{tabular}{lcc}
\hline & \multicolumn{2}{c}{$\alpha^{l o}=50$} \\
mortality & average GDP loss \\
\hline$\alpha^{l o}=1$ & 0.4385 & 0.0001 \\
$\alpha^{l o}=5$ & 0.4394 & 0.1207 \\
$\alpha^{l o}=10$ & 0.4559 & 0.2315 \\
\hline
\end{tabular}

Table 19: $p$-values for Mann-Whitney- $\mathrm{U}$ test between points from Figure 10 .

\begin{tabular}{lcc}
\hline & mortality & $\begin{array}{c}\text { Point A } \\
\text { average GDP loss }\end{array}$ \\
\hline Point B & $<0.0001$ & $<0.0001$ \\
Point C & 0.3702 & 0.0112 \\
Point D & $<0.0001$ & $<0.0001$ \\
Point E & 0.0021 & $<0.0001$ \\
\hline
\end{tabular}




\section{List of Variables}

Table 20: List of variables.

\begin{tabular}{|c|c|}
\hline Symbol & Description \\
\hline \multicolumn{2}{|l|}{ Firms } \\
\hline$A_{i}$ & Labor productivity \\
\hline$D_{i, w}$ & Sum of daily sales in the previous sales cycle \\
\hline$\hat{D}_{i, w}$ & Demand expectation for the production and sales cycle starting in week $w$ \\
\hline $\mathbf{F}_{w}$ & Set of all private firms \\
\hline $\mathbf{F}_{k, w}$ & Set of firms in sector $k$ \\
\hline$L_{i, w}^{n, w}$ & Labor input in the production and sales cycle starting in week $w$ \\
\hline$\tilde{L}_{i, w}{ }^{w}$ & Planned labor input for the production and sales cycle starting in week $w$ \\
\hline$L_{i, w}^{V}$ & Open vacancies in week $w$ \\
\hline$L_{i, w}^{R}$ & Redundancies in week $w$ \\
\hline$P_{i, w}$ & Price in week $w$ \\
\hline$\Pi_{i, w}$ & Profits of firm $i$ in the previous production cycle \\
\hline$Q_{i, w}$ & Realized output in the production and sales cycle of week $w$ \\
\hline$\tilde{Q}_{i, w}$ & Planned output for the production and sales cycle of week $w$ \\
\hline$S_{i, w}$ & Available liquidity in week $w$ \\
\hline$\tilde{S}_{i, w}$ & Threshold liquidity level for dividends in $w$ \\
\hline$X_{i, t}$ & Sales in period $t$ \\
\hline$Y_{i, t}$ & Inventory stock available for sale in period $t$ \\
\hline$c_{i}$ & Unit costs \\
\hline$c_{i}^{F}$ & Fixed costs \\
\hline$d_{i, w}$ & Dividends paid out by firm $i$ to its shareholders in week $w$ \\
\hline$\mu_{i, w}$ & Mark-up in week $w$ \\
\hline$n_{t}$ & Number of firms at time $t$ \\
\hline$n_{k, w}$ & Number of firms in sector $k$ in week $w$ \\
\hline$s_{i, w}$ & Market share of firm $i$ in week $w$ \\
\hline$w_{i}$ & Wage equal to sectoral wage $w_{k}$ \\
\hline \multicolumn{2}{|c|}{ Households } \\
\hline$C_{h, w}$ & Consumption budget \\
\hline$\tilde{C}_{h, k, t}^{S}$ & Intended consumption budget for sector $k$ \\
\hline $\mathcal{C}_{h, i, t}$ & Desired quantity of product $i$ \\
\hline$C_{h, k, t}^{S}$ & Actual consumption budget for sector $k$ \\
\hline$E_{h, t}^{n, k}$ & Total expenditures in period $t$ \\
\hline $\mathbf{H}_{t}$ & Set of all households at time $t$ \\
\hline $\mathbf{H}_{t}^{Y}$ & Set of all young households \\
\hline $\mathbf{H}_{t}^{O}$ & Set of all old households \\
\hline$I_{h, w}^{C a p}$ & Capital income of a household \\
\hline$I_{h, w}$ & Total gross income of a household \\
\hline$I_{h, w}^{N}$ & Total net income of a household \\
\hline $\bar{I}_{h, w}$ & Smoothed average net income of a household \\
\hline$W_{h, w}$ & Wealth of a household \\
\hline$m_{t}$ & Number of households at time $t$ \\
\hline
\end{tabular}


Table 20 - continued from previous page - List of variables

\begin{tabular}{ll}
\hline Symbol & Description \\
\hline$\omega_{h, w}$ & Wage of household $h$ in week $w$ \\
$u_{h, w}$ & Unemployment benefits of household $h$ in week $w$ \\
$w^{P}$ & Level of pension \\
\hline Labor market & \\
$\mathbf{L}_{k, w}^{S}$ & Set of workers forming the labor supply in sector $k$ \\
$L_{k, w}^{S}$ & Number of job seekers in sector $k$ \\
$\mathbf{L}_{k, w}^{H O}$ & Set of workers in sector $k$ that are eligible to work from home \\
$\mathbf{U}_{w}^{H}$ & Set of all unemployed households \\
$\mathbf{U}_{k, w}^{S}$ & Set of all unemployed households qualified for sector $k$ \\
$\mathbf{V}_{k, w}$ & Set of all firms of sector $k$ with open vacancies \\
$\mathbf{W}_{i, w}^{F}$ & Set employees of firm $i$ in week $w$ \\
$\mathbf{W}_{g}^{G}$ & Set of civil servants working for the public office $g$ \\
$\mathbf{W}_{i, t}^{H O}$ & Set of home office workers of $i$ at time $t$ \\
$\mathbf{W}_{i, t}^{S T}$ & Set of short time workers of $i$ at time $t$ \\
\hline
\end{tabular}

Goods market

$\mathbf{C}_{i, t} \quad$ Set of clients of firm $i$ at period $t$

$\mathbf{C}_{k, t} \quad$ Set of clients of a sectoral $k$ mall at period $t$

$\boldsymbol{\Omega}_{h, k, t} \quad$ Set of products of sector $k$ considered for consumption choice of household $h$

Social Interactions

$\mathbf{C S}_{h, k, t} \quad$ Set of co-shoppers of agent $h$ in sector $k$ at time $t$

$\mathbf{C W}_{h, t} \quad$ Set of co-workers of agent $h$ at time $t$

$N_{h, t}^{a, a} \quad$ Number of people met during social activities by agent $h$ at time $t$ divided per age group

$N_{h, k, t}^{c s} \quad$ Number of co-shoppers met by agent $h$ while shopping in sector $k$ at time $t$

$\bar{N}_{h, k, t}^{c s} \quad$ Maximum number of co-shopper eventually met by agent $h$ in sector $k$ at time $t$

$N_{h, t}^{c w} \quad$ Number of co-workers met by agent $h$ at time $t$

$\mathbf{S A}_{h, t}^{a} \quad$ Set of households belonging to a specific age group met by agent $h$ at time $t$ $\mathbf{X}_{h, t} \quad$ Set of colleagues of household $h$ at time $t$

Government

G $\quad$ Set of all public sector offices

$G D P_{w} \quad$ Gross domestic product of the previous week

$L^{P} \quad$ Number of civil servants working for the government

$S_{w}^{G} \quad$ Public account

$T_{w}^{C} \quad$ Corporate tax revenues

$T_{w}^{I} \quad$ Income tax revenue

$\mathbf{W}_{P, w}^{S} \quad$ The set of civil servants working for the government

$\tau_{w} \quad$ Tax rate

$\hat{\tau}_{w} \quad$ Reference tax rate

$w_{P}^{S} \quad$ Wage paid in the public sector

Pandemic

$\mathbf{D}_{t} \quad$ Set of deceased at time $t$

I $\quad$ Set of actual infected at time $t$ 
Table 20 - continued from previous page - List of variables

\begin{tabular}{ll}
\hline Symbol & Description \\
\hline $\mathbf{I}_{t}^{\text {inf }}$ & Set of infectious agents \\
$I_{h, t}^{2}$ & Cumulative number of secondary infection caused by agent $h$ at time $t$ \\
$\mathbf{R}_{t}$ & Set of recovered at time $t$ \\
$R_{0, t}$ & Daily basic reproduction number \\
$R_{0, t}^{R K I}$ & Robert Koch Institute reproduction number estimation \\
$\mathbf{S}_{t}$ & Set of susceptible at time $t$ \\
$\mathbf{T}_{t}$ & Set of new infected between time $t$ and $t+1$ \\
$q_{t}^{a}$ & Individual Case Fatality Rate at time $t$ \\
\hline \hline
\end{tabular}

\section{List of Parameters}

Table 21: List of parameters.

\begin{tabular}{|c|c|c|}
\hline Symbol & Description & Value \\
\hline \multicolumn{3}{|l|}{ Firms } \\
\hline$\left[\bar{A}_{k}\right]$ & Sector specific average productivity & {$[97,62,48,62]$} \\
\hline$\left[\beta_{k}\right]$ & $\begin{array}{l}\text { Target of firm savings relative to av. revenues } \\
\text { during last } 4 \text { weeks }\end{array}$ & {$[1,0.5,0.5,0]$} \\
\hline$\left[\chi_{k}\right]$ & Size of the sector specific weekly inventory buffer & {$[0.0036,0.0011,0.0018,0]$} \\
\hline$\left[\delta_{k}\right]$ & $\begin{array}{l}\text { Sector specific weekly depreciation rate of the } \\
\text { inventory }\end{array}$ & {$[0.01,1.00,0.50,0.00]$} \\
\hline$\left[e_{k}\right]$ & Estimated employment shares & {$[0.1170,0.4362,0.3268,0.1200]$} \\
\hline$\iota$ & Production boost in case of stock-out & 4 \\
\hline$\left[\lambda_{k}\right]$ & Weekly fixed to variable cost ratio & {$[0.0752,0.048,0.048,0.048]$} \\
\hline$n_{0}$ & Initial number of private firms & 3780 \\
\hline$\left[\bar{\mu}_{k}\right]$ & Upper bound firm mark-up & {$[0.18,0.18,0.18,0]$} \\
\hline$\left[\mu_{k}\right]$ & Lower bound firm mark-up & {$[0.25,0.25,0.25,0]$} \\
\hline$\left[p_{k}^{s}\right]$ & Probability of shopping $k \in\{M, S, F\}$ & {$[1,1,1]$} \\
\hline$\rho^{D}$ & Firm demand expectation smoothing & 0.5 \\
\hline$\zeta$ & Dividend payout ratio & 0.7 \\
\hline \multicolumn{3}{|c|}{ Households } \\
\hline$a_{0}^{y}$ & Fraction of the young households & 0.75 \\
\hline$\left[c_{k}\right]$ & Fixed consumption quotas & {$[0.21,0.50,0.29]$} \\
\hline$\eta$ & $\begin{array}{l}\text { Number of products from which households } \\
\text { choose consumption }\end{array}$ & 4 \\
\hline$\gamma^{c}$ & Intensity of consumer choice & 16 \\
\hline$\left[h_{k}^{H O}\right]$ & Sector proportion of home-office workers & {$[0.45,0.30,0.00,0.75]$} \\
\hline$\kappa$ & Adjustment wealth/income ratio & $0.1 / 4$ \\
\hline$m_{0}$ & Initial number of households & 100000 \\
\hline$\left[n_{k}^{w}\right]$ & $\begin{array}{l}\text { Work contact cardinality upper bound sector } \\
\text { specific }\end{array}$ & {$[8,8,8,8]$} \\
\hline$\left[n_{k}^{c}\right]$ & $\begin{array}{l}\text { Shopping contact cardinality upper bound sec- } \\
\text { tor specific (manufacturing, service, food) }\end{array}$ & {$[10,28,10]$} \\
\hline
\end{tabular}


Table 21 - continued from previous page - List of parameters

\begin{tabular}{|c|c|c|}
\hline Symbol & Description & Value \\
\hline$\left[n_{a, a}^{p}\right]$ & $\begin{array}{l}\text { Cross-age contact cardinality upper bound } \\
\text { yy,yo,oy,oo }\end{array}$ & {$[5,2,4,2]$} \\
\hline$\nu$ & Wage replacement rate & 0.60 \\
\hline$\Phi$ & Target wealth/income ratio & 32 \\
\hline$\phi$ & $\begin{array}{l}\text { Adjustment parameter consumption budget for } \\
\text { essential product }\end{array}$ & 0.01 \\
\hline$\left[\psi_{k}\right]$ & Wage factor & {$[0.7882,0.8078,0.8079,0.9542]$} \\
\hline$\rho^{I}$ & Income expectation smoothing & 0.4 \\
\hline \multicolumn{3}{|c|}{ Government } \\
\hline$n_{P}$ & Number of public offices & 600 \\
\hline pen & Pension as fraction of average wage & 0.50 \\
\hline$\varphi$ & Replacement rate of the short term program & 0.7 \\
\hline$\rho^{T}$ & Adjustment speed of the tax rate & 0.05 \\
\hline$\theta$ & $\begin{array}{l}\text { Fraction of public debt erased/added in one } \\
\text { week }\end{array}$ & $1 / 520$ \\
\hline \multicolumn{3}{|l|}{ Pandemic } \\
\hline$\delta_{r}$ & Detection rate & 0.15 \\
\hline$n^{i c u}$ & $\begin{array}{l}\text { Number of intensive care units available per } \\
\text { agent }\end{array}$ & $30 * 10^{-5}$ \\
\hline$p_{\text {inf }}$ & Infection probability in a single contact & 0.0725 \\
\hline$\left[\bar{q}_{l}^{a}\right]_{a=y, o}$ & $\begin{array}{l}\text { individual fatality rate with underutilization of } \\
\text { ICU }\end{array}$ & {$[0.00099,0.024]$} \\
\hline$\left[\bar{q}_{h}^{a}\right]_{a=y, o}$ & $\begin{array}{l}\text { individual fatality rate with overutilization of } \\
\text { ICU }\end{array}$ & {$[0.0027,0.075]$} \\
\hline$t_{0}$ & Starting date of the pandemic & 14 \\
\hline$t_{l n t}$ & Latency period of the disease & 5 \\
\hline$t_{\text {inf }}$ & Infectious period of the disease & 5 \\
\hline$t_{\text {gen }}$ & Generation time & 4 \\
\hline $\bar{t}_{r e c}$ & $\begin{array}{l}\text { Maximum number of days being infected or re- } \\
\text { covery time }\end{array}$ & 21 \\
\hline$t_{v a c}$ & $\begin{array}{l}\text { Number of days after the pandemic for vaccine } \\
\text { availability }\end{array}$ & 379 \\
\hline$u^{i c u}$ & $\begin{array}{l}\text { Fraction of infected people needing intensive } \\
\text { care }\end{array}$ & 0.01275 \\
\hline$\xi$ & $\begin{array}{l}\text { Reduction of infection probability coefficient de- } \\
\text { fault value }\end{array}$ & 0 \\
\hline
\end{tabular}

